\title{
Volatility Risk Pass-Through
}

\begin{abstract}
We produce novel empirical evidence on the relevance of output volatility (vol) shocks for both currency and international quantity dynamics. Focusing on G-17 countries, we document that: (1) consumption and output vols are imperfectly correlated within countries; (2) across countries, consumption vol is more correlated than output vol; (3) the pass-through of relative output vol shocks onto relative consumption vol is significant, especially for small countries; and (4) consumption differentials vol and exchange rate vol are disconnected. We rationalize these findings in a frictionless model with multiple goods and recursive preferences featuring a novel and rich risk-sharing of vol shocks.
\end{abstract}

JEL classification: C62; F31; G12.

First Draft: Febr 1, 2015. This draft: January 31, 2016. 


\section{Introduction}

The end of the Great Moderation period has highlighted once more the relevance of uncertainty shocks as key determinants of economic activity. In this paper, we estimate and explain the international transmission of output volatility shocks to both currencies and international quantity dynamics. More precisely, focusing on a large cross-section of major industrialized countries, we identify news to the conditional volatility of output, consumption and real exchange rates.

From this investigation we document several novel empirical findings. First, consumption and output volatilities are imperfectly correlated within countries. This implies that the growth rate of consumption in each country can experience changes in its conditional volatility that go beyond the arrival of endowment volatility shocks. Second, consumption volatility is more cross-country correlated than output volatil-

ity, suggesting that the output volatility shocks of one country propagate to the consumption of other countries.

In order to formalize the international propagation of output volatility shocks, we construct an index of volatility pass-through between two countries. Our index is equal to zero if a local output volatility shock results exclusively in an increase of local consumption volatility, without spilling over to the other country. Conversely, our index takes the value of 1 if a local output volatility shock results in an equal adjustment of consumption volatility in both countries.

We find that the pass-through of output volatility is sizeable, especially when the uncertainty shocks originate from the smallest countries in our cross-section. Specifically, when we focus on G7 countries, the pass-through is on the order of $50 \%$, regardless of the country in which the output volatility shock materializes. When we 
also include the next 10 countries according to their share of world GDP (henceforth G17), we find that the pass-through from bigger countries to smaller countries declines, whereas the pass-through of a volatility shock originating from small countries to large ones becomes as large as $70 \%$. That is, smaller countries can better share volatility shocks compared to larger countries, by redistributing a bigger fraction of their uncertainty shocks to their trading partners.

Our last empirical finding refers to the disconnect between the volatility of consumption differentials and the volatility of exchange rates. We document that the correlation of these volatilities is about $20 \%$ for the set of countries that we consider in our empirical investigation. This extent of comovement constitutes an anomaly from the standpoint of a frictionless model with time-additive preferences, since this setting prescribes an almost perfect correlation. This is a novel observation that goes beyond the low correlation of the levels of consumption differentials and exchange rates (Backus and Smith (1993) puzzle).

In the second part of this manuscript, we show that our main findings are an anomaly in the context of an equilibrium risk-sharing model with time-additive preferences. In contrast, when agents have recursive preferences, news about both future growth rates and future uncertainty are priced, thus they can jointly affect trade and volatility dynamics in a manner consistent with the data.

Specifically, we consider an economy with two countries, each populated by one agent with Epstein and Zin (1991) preferences (henceforth EZ preferences). Each agent is endowed with the stochastic supply of one country-specific good, whose dynamics are characterized by the presence of time-varying volatility shocks. Preferences feature a bias for the consumption of the domestic good. Trade occurs in friction- 
less goods markets and in financial markets featuring a complete set of state- and date-contingent securities.

Preferences are calibrated so that our agents dislike volatility of their continuation utilities. Since continuation utilities are a reflection of the entire future streams of consumption, we say that agents dislike long-run consumption variance. When news shocks hit the economy, agents have an incentive to trade in order to reduce the uncertainty of their future utility. Specifically, a country affected by a positive news shock will receive a lower share of resources, lower volatility of continuation utility going forward, but will also have higher short-run consumption volatility.

When news pertains to future expected growth rates, the international reallocation of resources results in an international exchange of both short-run and long-run consumption volatility across countries. That is, variances are characterized by negative comovements. We call this force the reallocation effect. News to output volatility, in contrast, produces a positive comovement in consumption volatilities across all countries: changes in output volatility spread in the cross-section of countries, with the reallocation channel only partially mitigating the effects of local shocks on local consumption volatility.

The recursive risk sharing arrangement that we described above is the key driver of our main results. Since agents dislike time-variation in the volatility of their consumption, they actively trade with each other in order to dampen the associated change in the volatility of consumption following an output volatility shock. This reallocation results in a marked degree of volatility pass-through, which brings our model closer to the data. 
We show that this channel is more pronounced when the endogenous distribution of international wealth is more spread out, i.e., when countries have different shares of world consumption. Consistent with the data, our model predicts that shocks to output volatility should come with a larger pass-through when they affect small countries. In a model with CRRA preferences, however, this result is missing as volatility shocks are not directly priced and the associated risk-sharing motive is absent.

Furthermore, the model can account for the small extent of positive comovement between the volatility of consumption differentials and the volatility of exchange rate's fluctuations thanks to two opposite forces. Volatility shocks tend to create positive correlation between the two volatilities, as they increase the uncertainty of all the variables in the economy. Long-run shocks, instead, generate a large negative comovement.

To better understand the role of long-run shocks, we note that they are responsible for most of the fluctuations of the wealth distribution. As the wealth distribution becomes more unequal, our countries depend more on each other in order to share risks. In equilibrium, they engage in more active trading and their stochastic discount factors become more correlated. By no arbitrage, the real exchange rate becomes less volatile. Simultaneously, the reallocation effect makes the cross-country difference of the consumption growth rates more volatile, as the pass-through of consumption volatility is not symmetric across countries with different wealth shares.

In a model without shocks to output volatility (e.g. Colacito and Croce (2013)), the volatility of the exchange rate and that of the international differential of consumption growth rates would be strongly negative because of the dominance of the reallocation channel. Since output volatility shocks increase the conditional volatility 
of all macroeconomic aggregates, positive comovements of volatility arises endogenously, partially offsetting the reallocation channel. Under our benchmark calibration, our recursive risk-sharing scheme produces a positive but moderate correlation between consumption differentials and exchange rate volatility, as in the data.

The international long-run risk literature has already documented the ability of long-lasting consumption news shocks to account for several empirical regularities of international asset prices (see, among others, Colacito (2008), Nakamura, Sergeyev, and Steinsson (2012), Colacito and Croce (2013), and Bansal and Shaliastovich (2013)). We differ from this literature in at least two dimensions. First, we provide novel evidence on the diffusion of fundamental output volatility shocks to consumption and currencies. Second, we provide an equilibrium explanation of our findings through the lens of a frictionless risk sharing scheme in which volatility shocks are priced.

Our manuscript contributes to a recently growing literature that studies uncertainty shocks in an international setting. In an early contribution, Ramey and Ramey (1995) show that countries with higher volatility of GDP have lower growth in the future. Consistent with their cross-sectional evidence, we find that higher domestic output volatility is associated with a decline in relative consumption in the future. We develop a general equilibrium model to study the implications of volatility risk sharing for quantities and prices.

Fogli and Perri (2015) link macroeconomic volatility to external imbalances trends in a neoclassical international production economy. Novy and Taylor (2014) nest uncertainty shocks in a model with endogenous production, international trade of intermediate inputs, and inventory concerns. They find that uncertainty shocks explain a relevant share of the cyclical behavior of trade and abstract away from asset pricing 
considerations. In contrast to them, we take output as given and link the diffusion of consumption uncertainty to currency behavior.

Fernandez-Villaverde, Guerron-Quintana, Rubio-Ramirez, and Uribe (2011) study interest rate uncertainty shocks in the context of a rich small open economy model with time-additive preferences. We study the propagation of uncertainty shocks in a general equilibrium exchange economy in which agents have recursive preferences and volatility shocks are priced. By doing so, we set the stage for a future class of macro-finance international business cycle models in which volatility shocks drive both international quantities and asset prices.

More broadly, our analysis relates to the recent literature which examines the role of uncertainty both in the data and in economic models (see, among others, Jones, Manuelli, Siu, and Stacchetti (2005), Justiniano and Primiceri (2008), Bloom (2009), Basu and Bundick (2012), Jurado, Ng, and Ludvigson (2014), and Gilchrist, Sim, and Zakrajsek (2014)).

Although our attention is focused on a frictionless risk-sharing setting with symmetric countries, we regard the introduction of frictions and heterogeneity in our model as an important directions for future research in this area (see, for example, Gabaix and Maggiori (2015), Ready, Roussanov, and Ward (2012), Backus, Gavazzoni, Telmer, and Zin (2010), Maggiori (2011), and Lustig, Roussanov, and Verdelhan (2011)). These frictions may be important to address the empirical link between uncertainty and international capital flows documented by Gourio, Siemer, and Verdelhan (2014).

Our study is also related to the growing body of literature that has investigated the macroeconomic foundations of international financial markets' fluctuations (see, 
inter alia, Farhi and Gabaix (2008), Hassan (2013), Stathopoulos (2012), HeyerdahlLarsen (2015), Verdelhan (2010), and Mueller, Stathopoulos, and Vedolin (2015)). We differentiate from these papers by explicitly introducing time-varying uncertainty in macroeconomic fundamentals and studying its effects on the optimal international risk-sharing arrangement.

Additionally, several papers have documented the relevance of higher order moments to sharpen our understanding of currency dynamics. Gavazzoni, Sambalaibat, and Telmer (2013) argue that non-gaussian dynamics of the stochastic discount factors are needed to reconcile the riskiness of currencies with the level of the interest rates. Zviadadze (2015) analyzes the relationship between shocks to the stochastic variance of US consumption to the cross-section of currency risk premia. Relative to this literature, we document how volatility shocks spread in the cross-section of G-17 countries and propose a model that accounts for how volatility risk is internationally shared. Furthermore, Farhi, Fraiberger, Gabaix, Ranciere, and Verdelhan (2015) and Chernov, Graveline, and Zviadadze (2015) study the role of crash risk for currency risk premia. We regard the introduction of rare events as an important generalization of this framework.

The manuscript is organized as follows. In Section 2 we describe our empirical strategy and our novel findings concerning the cross-section of volatilities of major industrialized countries. Section 3 describes our model, whose results are presented in Section 4. Section 5 concludes the paper. The Appendix contains additional robustness checks and the model's extensions. 


\section{Empirical Evidence}

In this section, we describe the econometric framework that we adopt to measure comovements in macroeconomic volatility within and across major industrialized coun-

tries. Focusing on the volatility of shocks to the growth rates of macroeconomic variables, we provide novel empirical evidence on the extent with which shocks to the relative volatility of GDP are transmitted to the relative vitalities of consumption. We refer to this concept as the volatility pass-through. Further, we provide evidence linking volatility comovements to trade dynamics.

\subsection{Data Description}

Sources and sample. Our empirical analysis is based on the cross-section of 17 major industrialized countries. After ranking these countries by GDP size, we have: the United States, Canada, France, Germany, Italy, Japan, United Kingdom, Australia, Belgium, Denmark, Netherlands, New Zealand, Norway, Portugal, Spain, Sweden, and Switzerland, respectively. In what follows, we refer to the group of first seven countries as G7, whereas the expanded set of countries is denoted as G17. We collect the national accounts, population, and CPI data from the Organization for Economic Cooperation and Development (henceforth OECD) database. The exchange rates, quoted as US dollar price of the foreign currency, are from the Federal Reserve Economic Database (henceforth FRED) database. The macroeconomic data are seasonally adjusted, real, and per capita.

In order to be consistent with the endowment economy that we analyze in sections 3 and 4, we abstract from both investment and public expenditure and compute aggregate output as the sum of consumption and net exports. Since our model is 
based on a frictionless risk-sharing scheme, we follow a common practice in this literature and let our quarterly dataset range from 1971:q1 to 2013:q4, a period of substantial financial integration across all major industrialized countries (see, among others, Quinn (1997), Obstfeld (1998), Taylor (2002), and Quinn and Voth (2008)) [1

Cross-sectional similarities and differences. Table 1 shows key moments of our international data. For ease of exposition, we report cross-sectionally aggregated moments, as opposed to country-level values. Specifically, we look at moments regarding both G7 and G17 countries. For G7 countries, we report the simple average of our aggregates. For G17 countries, we present both simple and GDP-weighted crosssectional averages of our moments. In order to assess the extent of cross-country heterogeneity, for each moment we also report its $1^{\text {st }}$ and $4^{\text {th }}$ quintile in the G17 group.

We highlight three relevant facts. First, the moments for the G7 group very much resemble those that are typically encountered for the US. As an example, consumption growth has a mean of about $2 \%$ per year and a volatility of about $1.75 \%$. In the G17 aggregate, the average growth rate declines, whereas the unconditional volatility of both output and consumption increases. In both cases, however, changes are relatively modest. Both quarterly consumption and output growth are almost serially uncorrelated.

Second, the average change in net-export-to-output ratio is distributed nearly symmetrically around zero. In the group of G17 countries, this moment ranges from $30 \%$ to $+34 \%$. Since smaller countries have more volatile output than bigger countries,

\footnotetext{
${ }^{1}$ Due to the data availability and quality issues, the data for Belgium, Norway, and Spain start in 1981, for New Zealand in 1986, and for Portugal in 1991. Our Bayesian methods can easily be applied to an unbalanced panel.
} 
Table 1: Data Summary Statistics

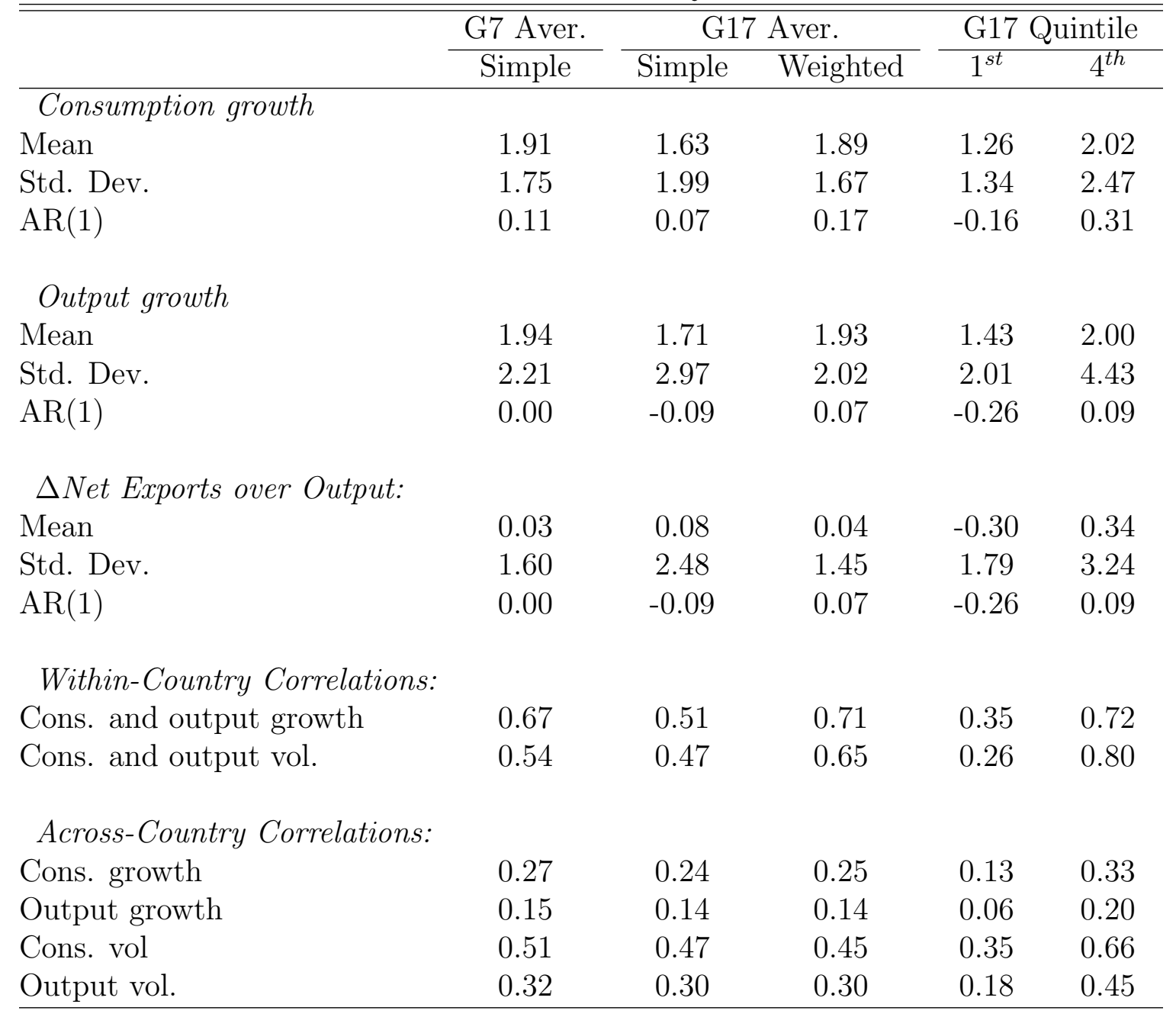

Notes - This Table shows summary statistics for consumption growth, output growth, change in net-export-to-output ratio, and consumption volatility, and output volatility. 'G7 Aver.' ('G17 Aver.') refers to simple (both simple and GDP-weighted) averages of key moments for G7 (G17) countries. The last two columns show the first and fourth quintiles of the moments of interest in the G17 cross-section. Macroeconomic variables are seasonally adjusted, real, and per capita. Means and volatilities are annualized, in per cent. Quarterly observations are from the 1971:Q1-2013:Q4 sample.

they tend to have also more volatile net-export-to-output ratios. In our model, we abstract away from this source of heterogeneity and focus on volatility of net-exportto-output ratios relative to output volatility. In the data this ratio is about 0.80 for both G7 and G17 countries. 
Third, both in the G7 and the G17 group, consumption growth rates feature low international correlations $2^{2}$ Further, output and consumption growth rates are imperfectly correlated within countries. Both of these empirical facts are consistent with the predictions of our recursive risk-sharing model.

In the next sections, we describe in detail our identification of the time-varying volatility components and address their comovements both within and across countries.

\subsection{Volatility Measurement and Co-movements}

We extract the volatility of the series of interest, $z_{t}$, by estimating the following specification

$$
\begin{gathered}
z_{t}=\mu(1-\rho)+\rho z_{t-1}+e^{\sigma_{t}(z) / 2} \eta_{t}, \\
\sigma_{t}(z)=\mu_{\sigma}(1-\nu)+\nu \sigma_{t-1}(z)+\sigma_{w} w_{t},
\end{gathered}
$$

where $\sigma_{t}(z)$ is a latent process equal to the logarithm of the variance of macroeconomic shock to $z_{t}$. The innovations $\eta_{t}$ and $w_{t}$ are independent gaussian shocks to the level and the volatility of $z_{t}$, respectively. The parameters $\rho$ and $\nu$ govern the persistence of $z_{t}$ and $\sigma_{t}\left(z_{t}\right)$, respectively, whereas $\mu$ and $\mu_{\sigma}$ represent the average level and volatility of $z_{t}$ and $\sigma_{t}\left(z_{t}\right)$, respectively. The parameter $\sigma_{w}$ captures the volatility of volatility.

Similar volatility specifications are entertained in Cogley and Sargent (2005) and Primiceri (2005) in the context of macroeconomic volatility, and Cortet, Sarno, and Tsiakas (2009) for financial volatility modeling. According to our specification, the

\footnotetext{
${ }^{2}$ The quantity anomaly in Backus, Kehoe, and Kydland (1994) does not apply to our dataset as our measured output excludes both investment and government expenditure.
} 
variance of $z_{t}$ is guaranteed to take on positive values. Although not reported in this manuscript, we have repeated our analysis by estimating directly volatility in levels, with very similar results. For this reason, in the remainder of this manuscript we shall refer to $\sigma_{t}$ as either log-volatility or volatility interchangeably.

We estimate the system of equations (2.1) following the Bayesian methods in Kim, Shephard, and Chib (1998). In each country, we fit our volatility specification to aggregate consumption and output growth separately. In order to check the robustness of our results, we also entertain a specification in which the volatility parameters are restricted to be common across countries and are jointly estimated in our cross-section of countries. In the interest of space, a complete summary of the estimation details is provided in the appendix.

Volatilities: aggregate time-pattern. Figure 1 shows our fitted volatilities aggregated across both G7 and G17 countries. For the G17 group, we also plot the first and the fourth cross-sectional volatility quintiles. Consistent with the findings of Table 1, consumption volatility is systematically lower than output volatility. Further, our estimation procedure captures the well-documented Great Moderation phenomenon, as both our estimated consumption and output volatilities slowly decline from the 1980s to the mid-2000s. These findings are consistent with those documented by Lettau, Ludvigson, and Wachter (2006), Stock and Watson (2002), and McConnell and Quiros (2000) for the United States, and support the plausibility of the results obtained so far.

Consistent with the unconditional evidence in Table 1, G17 countries have a larger average volatility level relative to the G7 group. In both country groups, our conditional estimates are subject to substantial and persistent fluctuations over time. More 


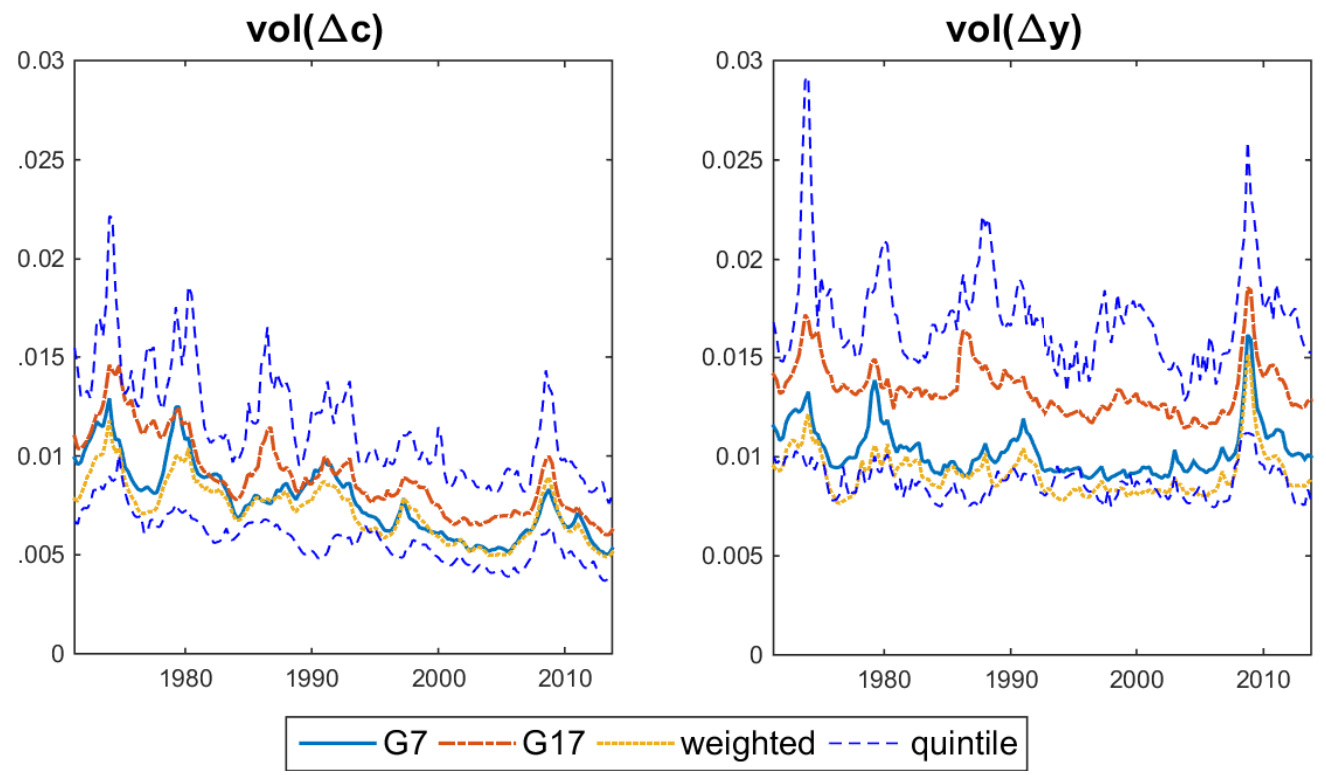

Figure 1 - Macroeconomic Volatilities. This Figure shows estimates of macroeconomic volatilities of real consumption and output growth. Volatilities, $e^{\sigma_{t} / 2}$, are estimated at a country level according to equation (2.1). The G7 line shows the equally-weighted crosssectional average for G7 countries. "G17" reports the equally-weighted average across all the G17 countries. "Weighted" reports the GDP-weighted average across G17 countries. Dashed lines show the first and fourth quantiles of the volatilities in the G17 cross-section. Quarterly observations range from 1971:Q1 to 2013:Q4.

broadly, the time pattern of the estimated aggregate volatilities shares similar characteristics across both G7 and G17 countries. These results suggest that our novel findings on international volatility comovements are quite general, as they apply to a large international cross-section.

Volatilities: comovements. Uncertainty shocks appear to be modestly correlated across countries. This statement applies to both consumption and output. In Table 1 , we formally quantify this statement by reporting volatility correlations within and across countries. We find that the correlation structure of the volatilities mimics the one of the levels.

Specifically, the cross-country correlation of endowments' volatilities is about 0.30 , a number close to the cross-country correlation of the levels of the growth rates. 
The cross-country correlation of consumption volatility is slightly higher than that of output volatility, once again consistently with that observed for the growth rates of the levels. Within each country, in contrast, the volatilities of consumption and output co-move strongly with each other. Their correlation is 0.70 , a figure similar to the one of consumption and output growth rates.

In our next step, we adopt a VAR approach to (i) better characterize the joint dynamics of both levels and volatilities, and (ii) quantify the pass-through of volatility shocks.

\subsection{Volatility Risk Pass-Through}

Relative volatility shocks. In order to evaluate the dynamic impact of shocks to relative volatility $\left(\sigma_{t}\left(\Delta y_{i}\right)-\sigma_{t}\left(\Delta y_{U S}\right)\right)$ across countries, we jointly estimate the following $N$ countries $\operatorname{VAR}(1)$ :

$$
\tilde{Y}_{t, i}=\tilde{\mu}_{Y, i}+\tilde{\Phi} \tilde{Y}_{t, i}+\tilde{\Sigma} \tilde{u}_{t, i}, \quad i=1,2, \ldots, N
$$

where

$$
\tilde{Y}_{i, t}=\left[\begin{array}{c}
\sigma_{t}\left(\Delta y_{i}\right)-\sigma_{t}\left(\Delta y_{U S}\right) \\
\Delta y_{i}-\Delta y_{U S} \\
\sigma_{t}\left(\Delta c_{i}\right)-\sigma_{t}\left(\Delta c_{U S}\right) \\
\Delta c_{i}-\Delta c_{U S} \\
\Delta(N X / Y)_{i}-\Delta(N X / Y)_{U S}
\end{array}\right]
$$

where $\Delta y_{i}-\Delta y_{U S}, \sigma_{t}\left(\Delta c_{i}\right)-\sigma_{t}\left(\Delta c_{U S}\right), \Delta c_{i}-\Delta c_{U S}$, and $\Delta(N X / Y)_{i}-\Delta(N X / Y)_{U S}$ denote the difference between country $i$ and the US of the growth rates of endowments, 
the volatilities of consumption growth rates, the growth rates of consumption and netexport-to-output ratios, respectively. We note that $N$ is equal to six for G-7 countries, and sixteen for G-17 countries.

Since we adopt the U.S. as the baseline home country throughout our analysis, this specification allows us to focus on relative bilateral adjustments computed with respect to a common benchmark. To sharpen the system's identification, we assume that the fundamental persistence and volatility parameters $\tilde{\Phi}$ and $\tilde{\Sigma}$ are common across countries, whereas the intercepts $\tilde{\mu}_{Y, i}$ are allowed to be country specific. Under these assumptions, we can estimate the VAR parameters by pooling the demeaned data across countries.

Throughout this study, we take volatility shocks as primitive exogenous innovations. Consistent with this approach, we identify impulse responses through a lower diagonal Cholesky decomposition in which output volatility shocks are the most exogenous to the system, i.e., they are ranked first. Using our estimated VAR, we can then trace the relative response of the macroeconomic variables to an increase in output volatility in foreign country relative to the US.

In Figure 2, we show the estimated impulse responses for the G7 countries to a relative volatility shock. In Table 2, we report the contemporaneous responses of all the variables in the system to this type of shock. These numbers correspond to the entries in the first column of the matrix $\tilde{\Sigma}$ in equation 2.2 . We perform this analysis for both the G7 and the remaining G17 countries (hereafter, we refer to this set of countries as bottom-10 G17). Our empirical evidence highlights several important cross-sectional aspects of volatility shocks across countries. 

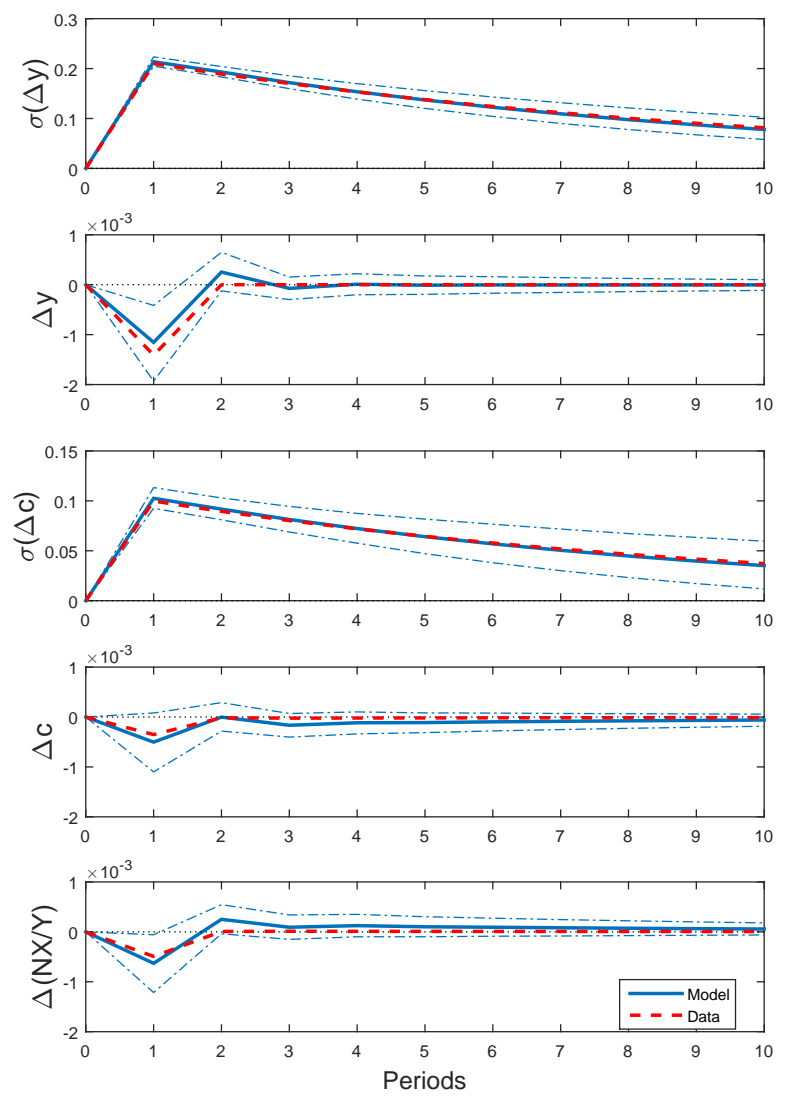

Figure 2 - Macroeconomic Responses to a Relative Volatility Shock. This Figure shows the estimates of the relative responses of the volatility and growth rate of output $(\Delta y)$, the volatility and growth rate of consumption $(\Delta c)$, and the change of net-export-tooutput ratio $(\Delta N X / Y)$ to a one-standard deviation increase in the volatility of output in foreign country relative to the U.S. Dashed (dotted) lines refer to the point estimates (95\% credible interval) of the $\operatorname{VAR}(1)$ specified in equation (2.3). Solid lines show the output from our model under the benchmark quarterly calibration reported in Table 4.

First, when country $i$ experiences an increase in its output volatility relative to the U.S., both its relative consumption and output growth rates fall. The estimated effects are large and almost always statistically significant. For example, in our G7 specification, foreign output growth falls by nearly half a percentage point relative to the U.S. upon the realization of a one-standard-deviation relative volatility shock. These findings complement the one-country evidence in Bansal, Kiku, Shaliastovich, and Yaron (2014) and Bloom (2009) in showing that an increase in domestic volatility 
Table 2: Volatility Risk Pass-Through

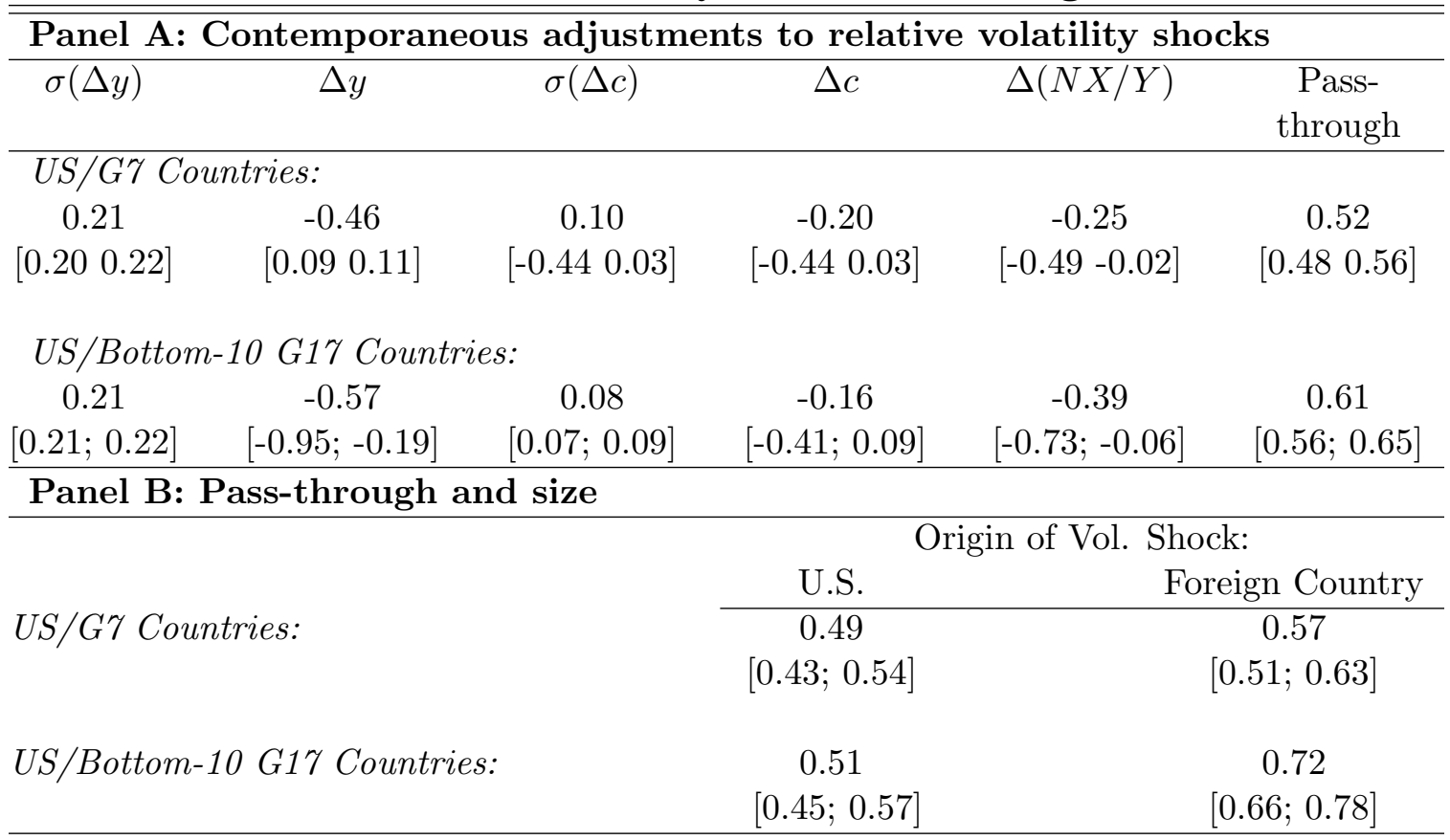

Notes - Panel A shows the estimates of the contemporaneous responses $\left(\widetilde{\Sigma}_{1 j}\right)$ of the $\operatorname{VAR}(1)$ specified in equations (2.2)-2.3) with respect to a shock to relative output volatility. Response of output growth, consumption growth, and net exports to output are annualized, in per cent. Volatility pass-through is defined as in equation 2.4. Panel B reports passthrough measures based on the estimates of the VAR in equation (2.5)-(2.6) with respect to volatility shocks affecting either the US or the remaining countries. $95 \%$ credible intervals are reported in the brackets. Our quarterly data range from 1971:q1 to 2013:q4.

decreases real economic activity. For the same country group, the fall in the relative level of consumption growth is about $0.20 \%$, i.e., half of that of output. This mitigation happens through net-imports, as the country with the highest volatility shock experiences a deterioration of its current account.

Second, upon the arrival of a relative increase in output volatility, the volatility of consumption increases as well. We find it convenient to explore this effect in greater detail, by defining a volatility pass-through index as follows: 


$$
\begin{aligned}
\text { Pass-through } & :=1-\frac{\partial\left(\sigma_{t}\left(\Delta c_{i}\right)-\sigma_{t}\left(\Delta c_{U S}\right)\right)}{\partial\left(\sigma_{t}\left(\Delta y_{i}\right)-\sigma_{t}\left(\Delta y_{U S}\right)\right)} \\
& =1-\widetilde{\Sigma}_{3,1} / \widetilde{\Sigma}_{1,1}
\end{aligned}
$$

where the second equality follows from our VAR specification. Since our analysis is based on country-pairs, this index is equal to zero if an increase in output's volatility in one country results in a one-for-one increase in its own consumption volatility. If instead an output volatility shock results in an equally redistributed increase in consumption volatility across the two countries, the volatility pass-through is 1 .

In an economy with time-additive preferences defined over one good, perfect risksharing implies a pass-through of one, as consumption is equalized across all possible states and hence $\sigma_{t}\left(\Delta c_{i}\right)-\sigma_{t}\left(\Delta c_{U S}\right)=0 \forall t$. Vice versa, in an endowment economy in which countries are subject to autarky, i.e., they cannot trade, our index is equal to zero, as $C_{i, t}=Y_{i, t} \forall i, t$ and hence $\left(\sigma_{t}\left(\Delta c_{i}\right)-\sigma_{t}\left(\Delta c_{U S}\right)\right)=\left(\sigma_{t}\left(\Delta y_{i}\right)-\sigma_{t}\left(\Delta y_{U S}\right)\right)$ $\forall i, t$.

Our estimates suggest that the volatility pass-through is about $50 \%$ for G7 countries, meaning that if country $i$ receives a country-specific output volatility shock of one, its own consumption volatility goes up by just 0.50 . This index increases further to $60 \%$ when we focus on smaller countries, suggesting that the international sharing of volatility shocks is more relevant for this set of countries. In our theoretical investigation, we show that replicating these results in a model with time-additive preferences is a challenge. 
Country-specific volatility shocks. The specification of the VAR in equation (2.3) is parsimonious, but it features three main shortfalls: (i) it does not provide information on the size of country-level shocks; (ii) it is silent on the correlation of shocks across countries; and (iii) it is unable to detect potentially different responses depending on whether volatility shocks arise from big or small countries. The first two limitations are relevant for calibration reasons. The third shortcoming limits our understanding of volatility shocks risk-sharing in the data.

To overcome these issues, we propose a slightly different VAR,

$$
Y_{t, i}=\mu_{Y, i}+\Phi Y_{t, i}+\Sigma u_{t, i}
$$

in which we disentangle foreign and U.S. variables:

$$
Y_{i, t}^{\prime}=\left[\begin{array}{llllll}
\sigma_{t}\left(\Delta y_{i}\right) & \sigma_{t}\left(\Delta y_{U S}\right) & \Delta y_{i} & \Delta y_{U S} & \sigma_{t}\left(\Delta c_{i}\right) & \sigma_{t}\left(\Delta c_{U S}\right)
\end{array}\right]
$$

As before, the persistence and scale matrices are common across countries, whereas the intercepts pick out country-specific differences in the means. For parsimony, we consider the smallest set of variables required for both calibration reasons and for the assessment of the volatility pass-through. As a result, we exclude both the change in net exports and the consumption growth rates from this VAR.

The estimation results used to guide our calibration are discussed in the next section and reported in Table 4. In panel B of Table2, we report the implied volatility pass-through due to either a one-standard deviation increase in U.S. output volatility, or a one-standard deviation in foreign output volatility for both the G7 and the bottom-10 G17 countries. The additional insight provided by this estimation is that the pass-through is sensitive to the size distribution of the countries that we analyze. 
Specifically, when we focus on the G7 group, all countries tend to have a similar size and a pass-through in the common range [51\%-54\%], regardless of the origin of the volatility shock. In contrast, when we focus on US versus the bottom-10 G17 countries, i.e., a cross-section with more dispersion in size, the origin of the shock matters. We find that the volatility pass-through is larger if the volatility shock originates from the smaller economies.

According to our estimates, the bottom-10 G17 countries have a pass-through of $72 \%$ when they receive an adverse output volatility shock. When the U.S. receives a volatility shock, in contrast, the pass-through to these smaller countries is just $51 \%$, a number comparable to that estimated among G7 countries. All together, these results suggest a novel empirical finding: after a spike in endowment uncertainty, small countries mitigate their consumption volatility better than large countries.

The volatility disconnect puzzle. If agents have CRRA preferences and markets are complete, the scaled difference of consumption growth rates should equal the rate of depreciation of the exchange rate between the two countries' currencies:

$$
\gamma \cdot\left(\Delta c_{h, t+1}-\Delta c_{f, t+1}\right)=\Delta e_{t+1}
$$

As a result, consumption growth rate differentials should be perfectly correlated with exchange rates. Starting from Backus and Smith (1993), a vast literature has documented the empirical failure of this prediction (hereafter, Backus and Smith puzzle). In the top part of Table 3, we show that Backus-Smith anomaly is present in our dataset as well. 
Table 3: Volatility Disconnect Puzzle

\begin{tabular}{|c|c|c|c|c|c|}
\hline & \multirow{2}{*}{$\begin{array}{c}\text { G7 Aver. } \\
\text { Simple }\end{array}$} & \multicolumn{2}{|c|}{ G17 Aver. } & \multicolumn{2}{|c|}{ G17 Quintile } \\
\hline & & Simple & Weighted & $1^{s t}$ & $4^{t h}$ \\
\hline Levels Disconnect & & & & & \\
\hline $\operatorname{corr}\left(\Delta c d_{t+1}, \Delta e_{t+1}\right)$ & -0.14 & -0.11 & -0.13 & -0.19 & -0.04 \\
\hline $\begin{array}{l}\operatorname{corr}\left(\Delta \widehat{c d}_{t+4}, \Delta \widehat{e}_{t+4}\right) \\
\quad \text { Volatility Disconnect }\end{array}$ & -0.14 & -0.17 & -0.14 & -0.29 & -0.05 \\
\hline $\operatorname{corr}\left(\sigma_{t}\left(\Delta c d_{t+1}\right), \sigma_{t}\left(\Delta e_{t+1}\right)\right)$ & 0.20 & 0.21 & 0.20 & -0.01 & 0.42 \\
\hline $\operatorname{corr}\left(\sigma_{t}\left(\Delta \widehat{c d}_{t+4}\right), \sigma_{t}\left(\Delta \widehat{e}_{t+4}\right)\right)$ & 0.27 & 0.25 & 0.26 & -0.02 & 0.52 \\
\hline
\end{tabular}

Notes - This Table shows correlations between the level and conditional volatility of consumption growth differentials $\left(c d_{t}^{i} \equiv \Delta c_{t}^{U S}-\Delta c_{t}^{i}\right)$ and exchange rate growth $\left(\Delta e_{t}^{i \mid U S D}\right)$, respectively. In both cases, the US is maintained as the benchmark home-country. $\mathrm{Cu}-$ mulative growth rates are denoted by ". 'G7 Aver.' ('G17 Aver.') refers to simple (both simple and GDP-weighted) averages of key moments for G7 (G17) countries. The last two columns show the first and fourth quintiles of the moments of interest in the G17 crosssection. Consumption is seasonally adjusted, real, and per capita. Volatility estimates are based on specification reported in equation (2.1). Quarterly observations are from the 1971:Q1-2013:Q4 sample.

Given our focus on the dynamics of volatility, we push our analysis one step forward and study the implications for the conditional variance of consumption growth differentials and the conditional variance of exchange rate's movements. Specifically, if we apply the conditional variance operator to both sides of equation (2.7), we get:

$$
\gamma^{2} \cdot \operatorname{Var}_{t}\left(\Delta c_{h, t+1}-\Delta c_{f, t+1}\right)=\operatorname{Var}_{t}\left(\Delta e_{t+1}\right)
$$

Equivalently, the correlation between the conditional variance of consumption differentials and exchange rate's movements should be equal to 1 .

As shown in the bottom portion of Table 3, empirically this correlation is very modest. We call this novel empirical fact the volatility disconnect puzzle. To the best of our knowledge, we are the first ones to both document the existence of this empirical anomaly, and address it in the context of a recursive risk-sharing equilibrium. 
Summarizing, our evidence shows that output volatility shocks decrease relative output and consumption across countries, and increase consumption volatility. In relative terms, the effects for consumption growth rate are smaller than for output growth rates, and the consumption volatility response is larger if output volatility shocks originate in a larger country. Equivalently, the pass-through from large to small countries is smaller than the pass-through from small to large countries. Furthermore, we find a strong disconnect between currency volatility and consumption differentials volatility. This empirical finding is an anomaly in the context of a frictionless risk-sharing model with CRRA preferences. In the next section, we develop an economic model which can explain and quantitatively replicate our volatility risk sharing evidence.

\section{Model}

The economy consists of two countries, home $(h)$ and foreign $(f)$, and two goods, $X$ and $Y$. Agents' preferences are defined over consumption aggregates of the two goods as follows.

Consumption aggregate. Let $x_{t}^{i}$ and $y_{t}^{i}$ denote the consumption of $\operatorname{good} X$ and good $Y$ in country $i \in\{h, f\}$ at date $t$. Let $\alpha \in(0,1)$. The consumption aggregates in the home and foreign countries are

$$
C_{t}^{h}=\left(x_{t}^{h}\right)^{\alpha}\left(y_{t}^{h}\right)^{1-\alpha} \quad \text { and } \quad C_{t}^{f}=\left(x_{t}^{f}\right)^{1-\alpha}\left(y_{t}^{f}\right)^{\alpha}
$$


respectively. The parameter $\alpha$ captures the degree of bias of the consumption of each representative agent. In what follows we assume that the home country is endowed with good $X$, while the foreign country is endowed with good $Y$. Following some of the international macrofinance articles surveyed by Lewis (2011), we assume that $\alpha$ is larger than 0.5. This allows us to build consumption home bias into the model.

Preferences. As in Epstein and Zin (1993), agents' preferences are recursive but not time-separable:

$$
U_{t}^{i}=\left[(1-\delta) \cdot\left(C_{t}^{i}\right)^{1-1 / \psi}+\delta E_{t}\left[\left(U_{t+1}^{i}\right)^{1-\gamma}\right]^{\frac{1-1 / \psi}{1-\gamma}}\right]^{\frac{1}{1-1 / \psi}}, \quad \forall i \in\{h, f\}
$$

The coefficients $\gamma$ and $\psi$ measure the relative risk aversion (RRA) and the IES, respectively.

In contrast to the constant RRA case, these preferences allow agents to be risk averse in future utility as well as future consumption. The extent of such utility risk aversion depends on the preference for early resolution of uncertainty measured by $\gamma-1 / \psi>0$. To better highlight this feature of the preferences, we focus on the ordinally equivalent transformation

$$
V_{t}=\frac{U_{t}^{1-1 / \psi}}{1-1 / \psi}
$$

and approximate it with respect to $\theta \equiv \frac{\gamma-1 / \psi}{1-1 / \psi}$ around $\theta_{0}=1$

$$
\begin{aligned}
V_{t} & =(1-\delta) \frac{C_{t}^{1-1 / \psi}}{1-1 / \psi}+\delta E_{t}\left[V_{t+1}^{1-\theta}\right]^{\frac{1}{1-\theta}} \\
& \approx(1-\delta) \frac{C_{t}^{1-1 / \psi}}{1-1 / \psi}+\delta E_{t}\left[V_{t+1}\right]-\frac{\delta}{2} \frac{\theta}{E_{t}\left[V_{t+1}\right]} \operatorname{Var}_{t}\left[V_{t+1}\right]
\end{aligned}
$$


Note that the sign of $\left(\frac{\theta}{E_{t}\left[V_{t+1}\right]}\right)$ depends on the sign of $(\gamma-1 / \psi)$. When $\gamma=1 / \psi$, the agent is utility-risk neutral and preferences collapse to the standard time-additive case. When the agent prefers early resolution of uncertainty, that is, when $\gamma>1 / \psi$, the coefficient $\theta$ is positive: uncertainty about continuation utility reduces welfare and generates an incentive to trade off future expected utility, $E_{t}\left[V_{t+1}\right]$, for future utility risk, $\operatorname{Var}_{t}\left[V_{t+1}\right]$.

This mean-variance trade-off is absent when agents have standard time-additive preferences, and it represents the most important element of our analysis given our focus on the propagation of uncertainty shocks.

Since there is a one-to-one mapping between utility, $U_{t}^{i}$, and lifetime wealth, that is, the value of a perpetual claim to consumption, $W_{c, t}^{i}$,

$$
U_{t}^{i}=\left[(1-\delta)\left(C_{t}^{i}+W_{c, t}^{i}\right)\right]^{\frac{1}{1-1 / \psi}}, \quad \forall i \in\{h, f\}
$$

the optimal risk-sharing scheme can also be interpreted in terms of the mean-variance trade-off of wealth. For this reason, in what follows we use the terms "wealth" and "continuation utility" interchangeably.

Endowments. We choose to endow each country with a stochastic supply of its most-preferred good. Endowments account for time-varying risk and are modeled in the spirit of Colacito and Croce (2013)

$$
\begin{aligned}
\Delta \log X_{t} & =\mu_{x}+z_{1, t-1}+e^{\sigma_{x, t} / 2} \sigma \varepsilon_{x, t}-c i_{t-1} \\
\Delta \log Y_{t} & =\mu_{y}+z_{2, t-1}+e^{\sigma_{y, t} / 2} \sigma \varepsilon_{y, t}+c i_{t-1},
\end{aligned}
$$


where the process $c i_{t} \equiv \tau \log \left(X_{t} / Y_{t}\right)$ with $\tau \in(0,1)$ introduces cointegration and guarantees the existence of the equilibrium, and the components $z_{1}$ and $z_{2}$ are highly persistent $\mathrm{AR}(1)$ processes,

$$
z_{j, t}=\rho z_{j, t-1}+\sigma_{z} \varepsilon_{j, t}, \forall j \in\{1,2\}
$$

Throughout the paper, we refer to $\varepsilon_{1, t}$ and $\varepsilon_{2, t}$ as long-run shocks, due to their longlasting impact on the growth rates of the two endowments. Similarly, we call $\varepsilon_{x, t}$ and $\varepsilon_{y, t}$ short-run shocks.

We focus on time-varying short-run risk, as captured by the following process:

$$
\sigma_{j, t}=\rho_{\sigma} \sigma_{j, t-1}+\sigma_{s r} \varepsilon_{\sigma j, t}, \forall j \in\{x, y\}
$$

Shocks are jointly log-normal:

$$
\xi_{t} \equiv\left[\begin{array}{llllll}
\varepsilon_{1, t} & \varepsilon_{2, t} & \varepsilon_{x, t} & \varepsilon_{y, t} & \varepsilon_{\sigma 1, t} & \varepsilon_{\sigma 2, t}
\end{array}\right] \sim \quad \text { i.i.d.N }(\mathbf{0}, \Sigma)
$$

and the matrix $\Sigma$ is assumed to be block-diagonal to allow for cros-country correlation of shocks of the same type.

Markets. At each date, trade occurs in a complete set of one-period-ahead claims to state-contingent consumption. Financial and goods markets are assumed to be frictionless. The budget constraints of the two agents can be written as

$$
\begin{aligned}
& x_{t}^{h}+p_{t} y_{t}^{h}+\int_{\zeta^{t+1}} A_{t+1}^{h}\left(\zeta^{t+1}\right) Q_{t+1}\left(\zeta^{t+1}\right)=A_{t}^{h}+X_{t} \\
& x_{t}^{f}+p_{t} y_{t}^{f}+\int_{\zeta^{t+1}} A_{t+1}^{f}\left(\zeta^{t+1}\right) Q_{t+1}\left(\zeta^{t+1}\right)=A_{t}^{f}+p_{t} Y_{t},
\end{aligned}
$$


where $p_{t}$ denotes the relative price of goods $X$ and $Y$ (the terms of trade), $A_{t}^{i}\left(\zeta^{t}\right)$ denotes country $i$ 's claims to time $t$ consumption of good $X$, and $Q_{t+1}\left(\zeta^{t+1}\right)$ gives the price of one unit of time $t+1$ consumption of good $X$ contingent on the realization of $\zeta^{t+1}$ at time $t+1$. In equilibrium, the market for international state-contingent claims clears, implying that $A_{t}^{h}+A_{t}^{f}=0, \forall t$.

Prices. The stochastic discount factor in consumption aggregate units is

$$
M_{t+1}^{i}=\delta\left(\frac{C_{t+1}^{i}}{C_{t}^{i}}\right)^{-\frac{1}{\psi}}\left(\frac{U_{t+1}^{i 1-\gamma}}{E_{t}\left[U_{t+1}^{i 1-\gamma}\right]}\right)^{\frac{1 / \psi-\gamma}{1-\gamma}}
$$

Since markets are assumed to be complete, the log growth rate of the real exchange rate is

$$
\Delta e_{t}=\log M_{t}^{f}-\log M_{t}^{h}
$$

and the relative price of the two goods is $p_{t}=\frac{(1-\alpha) x_{t}^{h}}{\alpha y_{t}^{h}}$.

Allocations. Under complete markets, we can compute efficient allocations by solving the associated Pareto problem. The planner attaches date 0 nonnegative Pareto weights $\mu^{h}=\mu$ and $\mu^{f}=1-\mu$ to the consumers and chooses the sequence of allocations $\left\{x_{t}^{h}, x_{t}^{f}, y_{t}^{h}, y_{t}^{f}\right\}_{t=0}^{+\infty}$ to maximize

$$
\Lambda=\mu \cdot U_{0}^{h}+(1-\mu) \cdot U_{0}^{f}
$$


subject to the following sequence of economy-wide feasibility constraints:

$$
\begin{aligned}
x_{t}^{h}+x_{t}^{f} & =X_{t} \\
y_{t}^{h}+y_{t}^{f} & =Y_{t}, \quad \forall t \geq 0,
\end{aligned}
$$

where the state-dependent notation is omitted for the sake of clarity. In characterizing the equilibrium, we follow Anderson (2005) and formulate the problem using the ratio of time-varying pseudo-Pareto weights, $S_{t}=\mu_{t} /\left(1-\mu_{t}\right)$, as an additional state variable. This technique enables us to take into account the nonseparability of the utility functions.

The first-order necessary conditions imply the following allocations:

$$
\begin{aligned}
x_{t}^{h}=\alpha X_{t}\left[1+\frac{(1-\alpha)\left(S_{t}-1\right)}{1-\alpha+\alpha S_{t}}\right], & x_{t}^{f}=(1-\alpha) X_{t}\left[1-\frac{\alpha\left(S_{t}-1\right)}{1-\alpha+\alpha S_{t}}\right] \\
y_{t}^{h}=(1-\alpha) Y_{t}\left[1+\frac{\alpha\left(S_{t}-1\right)}{\alpha+(1-\alpha) S_{t}}\right], & y_{t}^{f}=\alpha Y_{t}\left[1-\frac{(1-\alpha)\left(S_{t}-1\right)}{\alpha+(1-\alpha) S_{t}}\right],
\end{aligned}
$$

where

$$
S_{t}=S_{t-1} \cdot \frac{M_{t}^{h}}{M_{t}^{f}} \cdot\left(\frac{C_{t}^{h} / C_{t-1}^{h}}{C_{t}^{f} / C_{t-1}^{f}}\right), \quad \forall t \geq 1
$$

and $S_{0}=1$, as we start the economy from an identical allocation of wealth and endowments. This is consistent with the ergodic distribution of the model, which implies that on average the two countries consume an identical share of world resources because of symmetry. 
We make three remarks. First, $S_{t}$ is a key driver of the share of world consumption allocated to the home country, $S W C_{t}$,

$$
S W C_{t}=\frac{x_{t}^{h}+p_{t} y_{t}^{h}}{X_{t}+p_{t} Y_{t}}=\frac{S_{t}}{1+S_{t}} .
$$

The higher $S_{t}$, the larger the home country. Second, as in Colacito and Croce (2013), when the home country receives good news for the endowment of good $X$, there is a persistent reduction in the domestic share of world consumption. This countercyclical adjustment is consistent with equation (3.12): as good news for the supply of good $X$ relative to good $Y$ materializes, the home country experiences a drop in its marginal utility. Therefore, it is optimal to reallocate resources to the foreign country. In the decentralized economy, the home country optimally substitutes part of its current consumption with exports to its foreign trading partner. Third, $S_{t}$ introduces an endogenous time-varying volatility term into consumption growth, since allocations are nonlinear functions of this component. In Section 4.3, we discuss the importance of this channel in the context of our explanation of the volatility disconnect anomaly.

\subsection{Calibration and Solution Method.}

We report our benchmark calibration in table 4. Panel A refers to parameters that have already been employed in this class of models and are standard in the literature (see, among others, Colacito and Croce (2011), Colacito and Croce (2013), and Bansal and Shaliastovich (2013)).

We set the intertemporal elasticity of substitution to 1.5, as in Colacito and Croce (2013). Because of the presence of volatility risk, we can obtain a volatile stochastic 
Table 4: Calibration

\begin{tabular}{lcc}
\hline \hline Description & Parameter & Value \\
\hline Panel A: Standard Parameters & $\gamma$ & 7 \\
Relative Risk Aversion & $\psi$ & 1.50 \\
Intertemporal Elasticity of Substitution & $\delta^{4}$ & 0.98 \\
Subjective Discount Factor & $\alpha$ & 0.96 \\
Degree of Home Bias & & \\
& $\mu \cdot 4$ & $2.00 \%$ \\
Mean of Endowment Growth & $\sigma \cdot \sqrt{4}$ & $1.87 \%$ \\
Short-Run Risk Volatility & $\rho^{4}$ & 0.953 \\
Long-Run Risk Autocorrelation & $\sigma_{z} / \sigma$ & $6.90 \%$ \\
Relative Long-Run Risk Volatility & & 00.15 \\
& $\rho_{X}$ & 00.92 \\
Cross-correlation of Short-Run Shocks & $\rho_{z}$ & \\
Cross-correlation of Long-Run Shocks & & 0.90 \\
Panel B: Time-Varying Short-Run Risk & & $0.89-0.93]$ \\
Persistence of Short-Run Volatility & $\rho_{\sigma}$ & 0.15 \\
& & $0.15-0.16]$ \\
Volatility of Short-Run Volatility & $\sigma_{s r}$ & 0.30 \\
Cross-correlation of Short-Run Volatility & & $\rho_{\sigma, \sigma^{*}}$ \\
Short-Run Volatility Correlation with & & $-0.13-0.45]$ \\
Short-Run Shocks & $\rho_{\sigma, \Delta y}$ & {$[-0.15-0.05]$} \\
\hline
\end{tabular}

Notes - All parameters are calibrated at quarterly frequency. In Panel B, the entries for the data are from the VAR specified in equations (2.5)-(2.6). Numbers in brackets denote the bayesian $95 \%$ credible set. Data are from the OECD dataset and refer to G-17 countries. The sample spans the post-Bretton Wood period, 1971:q1-2013:q4.

discount factor with a risk aversion coefficient of 7 , a value particularly conservative in this literature. The subjective discount factor is chosen so as to keep the average annual risk free-rate close to $1 \%$ when possible.

The consumption home-bias is set to 0.96 , a number that falls in the middle of the range observed for our countries. For example, in our sample the U.S. home-bias is 0.95 , as an average of $5 \%$ of U.S. consumption goods are composed of imports (Erceg, Guerrieri, and Gust (2008)). Balta and Delgado (2007) document a stronger 
consumption home bias for the European countries in our dataset and suggest a value of $\alpha=0.97$. Setting $\lambda=0.97$ would improve our quantitative results, as it would make our risk-sharing channel even more relevant. We prefer to work with $\alpha=0.96$ in order to obtain conservative results.

Annualized average output growth is set to $2 \%$, consistent with the empirical findings in Table 1. Unconditional volatilities are calibrated to produce an unconditional output volatility of $1.90 \%$, as in the data. The long-run components are calibrated in the spirit of the international long-run risk literature, as they are both highly persistent and correlated across countries (Colacito and Croce (2011), Colacito and Croce (2013)). Since we set $\sigma_{z} / \sigma=0.07 \%$, the implied consumption growth rate is almost i.i.d., as in the data. Short-run output growth shocks, in contrast, are as poorly cross-country correlated as output growth in our dataset (see Table 1).

In Panel B, we report the parameters that govern the volatility process of shortrun shocks, i.e., the novel and most important element of our investigation. These parameters are calibrated to be consistent with our empirical results. Specifically, we pick values typically in the middle of the bayesian $95 \%$ credible intervals of the VAR system specified in equations $2.5-2.6$.

Consistent with our data, volatility shocks are as poorly correlated across countries as short-run growth shocks. We allow for negative within-country correlation between volatility and short-run growth shocks so that higher volatility is associated to economic slowdowns. Conditional volatilities are as persistent as in the data.

Given these parameters, we use perturbation methods to solve our system of equations. We compute an approximation of the third order of our policy functions using the dynare++ package. As documented in Colacito and Croce (2012), a third- 
order approximation is required to capture endogenous time-varying volatility due to the adjustments of the pseudo-Pareto weights. All variables included in our dynare++ code are expressed in log-units.

Both the calibration and the solution methods are standard in the literature. In what follows we discuss only the performance of our model for the dynamics of conditional volatilities, i.e., the main objective of our investigation. For commonly targeted unconditional moments, we defer the reader to Table $\mathrm{B} 2$ in the Appendix. For the sake of completeness, the table also shows the same moments for the case in which we abstract away from volatility shocks, and for the setting with CRRA preferences.

\section{Main Results}

In this section, we present the main result of our theoretical analysis. We start by describing the risk-sharing motives of both level and volatility shocks. We are the first ones to connect recursive risk-sharing to our evidence on consumption volatility dynamics both within country and in the cross-section of countries. We then assess the quantitative performance of our model by means of simulations and show that a frictionless recursive risk-sharing scheme can rationalize our empirical findings.

\subsection{Risk Sharing Motives}

Risk-sharing of level shocks. In Figure 3(a), we report the response of the variables of interest to a short-run level shock (left panels) and to a long-run level shock (right panels) to the growth rate of the endowment of the home country. Note that on 

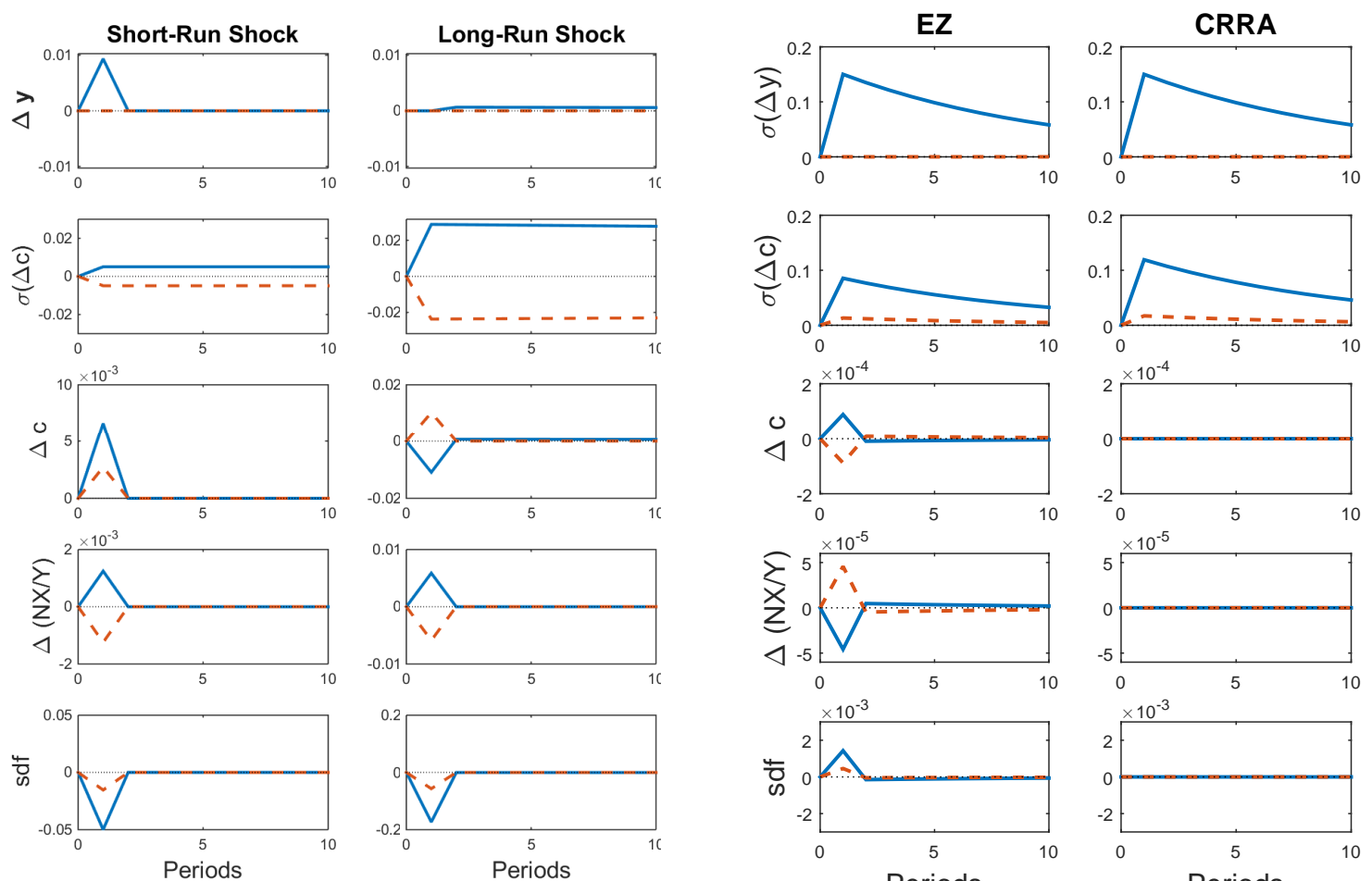

- HOME - - FOREIGN

(a) Level Shocks (EZ only)

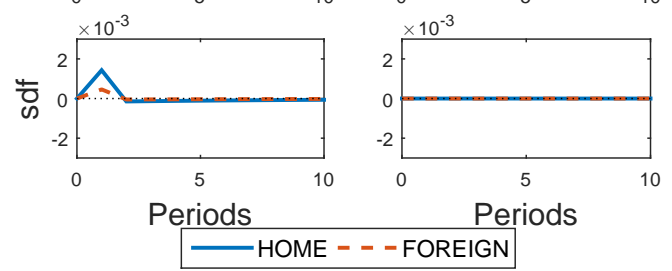

(b) Vol Shock (EZ vs CRRA)

Figure 3 - Impulse Responses. Panel (a) shows the percentage impulse response functions of output growth $(\Delta y)$, consumption growth volatility $(\sigma(\Delta c))$, consumption growth $(\Delta c)$, change of net-export-output ratio $(\Delta N X / Y)$, and stochastic discount factors $(s d f)$ to a shock to the home endowment for both the home country (solid line) and the foreign country (dashed line). Level shocks materialize only in the home country, and only at time 1. Shocks are not orthogonalized; we consider a positive $\sigma$ shock in the short-run, and a positive $\sigma_{x}$ shock for the long-run. In panel (b) we consider an endowment volatility shock which is orthogonalized within and across countries, i.e., it affects only the home country and it does not change the growth rate level. All parameters are calibrated to the quarterly values reported in Table 4.

impact the short-run shock is sizeably larger compared to the long-run shock (panels of the first row of Figure 3(a). However, the long-run shock is highly persistent and it ends up affecting the growth rate of the home endowment for a large number of periods. 
Consistent with Colacito and Croce (2013), the growth rates of consumption increase in both countries in response to a positive short-run shock, whereas they move in opposite directions in response to a positive long-run shock (panels on the third row of Figure 3(a). The asymmetric response of consumption growth rates to a long-run endowment shock is the result of the agents' extreme sensitivity to persistent news to the growth rates of their endowments.

When a shock of this nature materializes, the home country's marginal utility drops substantially (second panel on the last row of Figure 3(a). In order to restore the equality of the marginal utilities of consumption across countries, an international redistribution of resources needs to take place. Specifically, the home country increases its exports, while the foreign country increases its imports (panels of the fourth row of Figure $3(\mathrm{a})$. Equivalently, the ratio of the pseudo-Pareto weights $S_{t}$ declines, as dictated by equation $(3.12$ ).

Since the long-run shock is a pure news shock, i.e., a shock that results in a larger amount of home endowment only in future time periods, the international redistribution of resources takes place through a drop in home consumption and an increase in foreign consumption. As pointed out in Colacito and Croce (2013), this immediate response of the consumption level simultaneously comes with an opposite swap of long-run consumption variance (as measured by $\sigma_{t}\left(U_{t+1}\right)$ ). Specifically, the home country optimally reduces its current consumption share, $S_{t} /\left(1-S_{t}\right)$, in exchange for a reduction in $\sigma_{t}\left(U_{t+1}\right)$ (see Figure 4 , top-right panel). Consistent with equation (3.3), the reduction of long-term uncertainty improves welfare.

Given our interest for both the volatility pass-through and the volatility disconnect anomaly, we pay particular attention to the response of the volatility of consumption 
growth rates, $\sigma_{t}\left(\Delta c_{t+1}^{i}\right)$. These variables have never been studied before and warrant further discussion.

First of all, we highlight that their qualitative response is similar following both a short- and a long-run shock (second row of Figure 3(a)). Indeed in both cases, the volatility of consumption growth rate of the country that experiences the positive endowment shock increases, whereas the volatility of consumption declines for the other country. As depicted in the top-left panel of Figure 4, this response is the direct result of the negative link between pseudo-Pareto weight and consumption volatility generated under EZ preferences.

The top-right panel of the same figure illustrates that the recursive risk-sharing mechanism of this economy is characterized by the agents' willingness to trade-off short-term consumption risk (i.e., $\sigma_{t}\left(\Delta c_{t+1}\right)$ ) for a smoother future consumption profile (i.e., $\left.\sigma_{t}\left(U_{t+1}\right)\right)$. That is, savings are dynamically adjusted to achieve long-run consumption smoothing at the cost of increasing short-run consumption volatility. In both panels, we also show that with CRRA preferences this trade-off is absent.

The bottom two panels of figure 4 document that the response of short-term consumption volatility in our benchmark model is generated by the interaction of recursive preferences with long-run growth news shocks. Absent these shocks, continuation utilities are very smooth and agents have a negligible incentive to reducing their utility's volatility any further through an increase in short-term consumption fluctuations.

A second important lesson from Figures $3(\mathrm{a})$ and 4 is that the absolute change in volatility for the country that is affected by a positive level shock (i.e., negative adjust- 

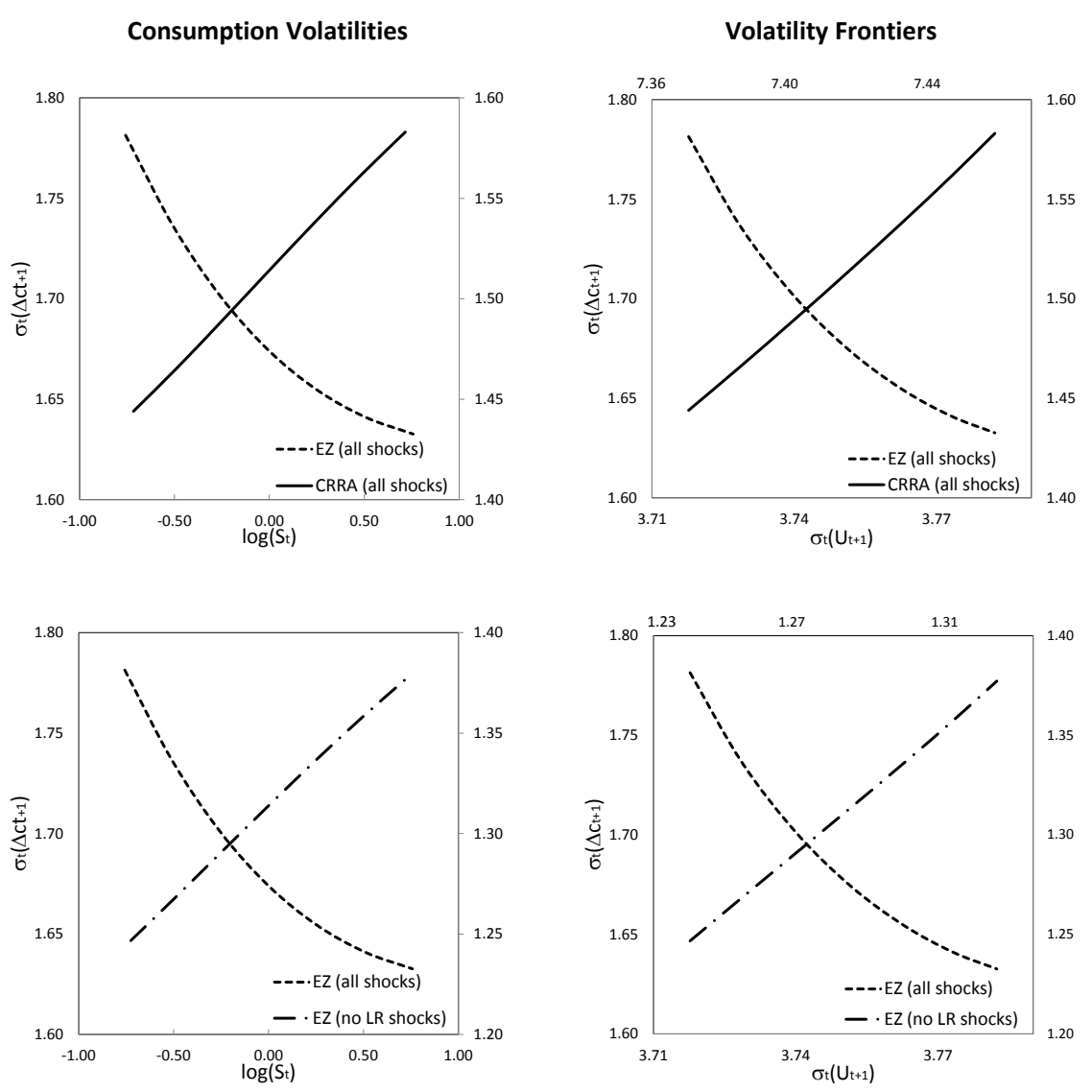

Figure 4 - Variance Frontiers. The left panels report the the conditional volatility of the growth rate of consumption in the home country $\left(\sigma_{t}\left(\Delta c_{h, t+1}\right)\right)$ as a function of the logarithm of the ratio of pseudo-Pareto weights $\left(s_{t}\right)$. In the right panels we replace the logarithm of the ratio of pseudo Pareto weights with the associated conditional volatility of the normalized continuation utility in the home country (i.e., $\sigma_{t}\left(U_{h, t+1} /\left(X_{t}^{\alpha} Y_{t}^{1-\alpha}\right)\right)$ ). In the left panels, the left (right) axis reports the values for our benchmark (alternative) calibration. In the right panels, the values for our benchmark (alternative) calibration are reported on the left and bottom (top and right) axes. Across all experiments, we keep both the exogenous long-run components and the exogenous volatility processes fixed at their unconditional mean.

ment in its pseudo-Pareto weight) is larger than the absolute change in the volatility for the other country. Equivalently, the short-run consumption volatility frontier is convex. This asymmetry is due to the concavity of the consumption aggregator with respect to $S_{t}$. As a result, the variation of the share of world consumption produces 
bigger variability in the consumption aggregate of smaller countries, an important feature to explain our evidence on the volatility pass-through.

Risk-sharing of vol shocks. Figure $3(\mathrm{~b})$ shows the response of our main set of variables of interest to a volatility shock in the home country. For comparability, we report the responses from both our benchmark model and a model with standard time-additive CRRA preferences.

First of all, we note that the relative response of the volatilities of consumption growth rates in the two countries differs across the two preference specifications. With CRRA preferences, volatility news are not directly priced and hence marginal utilities do not move. There is no reallocation of resources across countries and as a result the increase in volatility of the domestic endowment is almost entirely absorbed by domestic consumption. According to our definition of volatility pass-through, in this situation our index takes on a value close to zero.

In the specification with EZ preferences, the risk-sharing motive that we described in the previous section partially offsets the increased amount of volatility in the economy. As documented in the left panel of Figure 5, upon the arrival of an adverse volatility shock, the short-run consumption volatility frontier of the home country shifts upward by a lesser extent than under CRRA preferences. Since our agents are averse to conditional variance, their trade is arranged to reduce the time-variation of their own conditional volatilities. Furthermore, these countries tend to keep their volatilities aligned to each other. As shown in the right panel of Figure 5, the crosscountry difference of the conditional volatilities increases by a smaller amount under EZ preferences than under the CRRA setting. We discuss this finding in further detail in our next section when discussing our volatility pass-through results. 

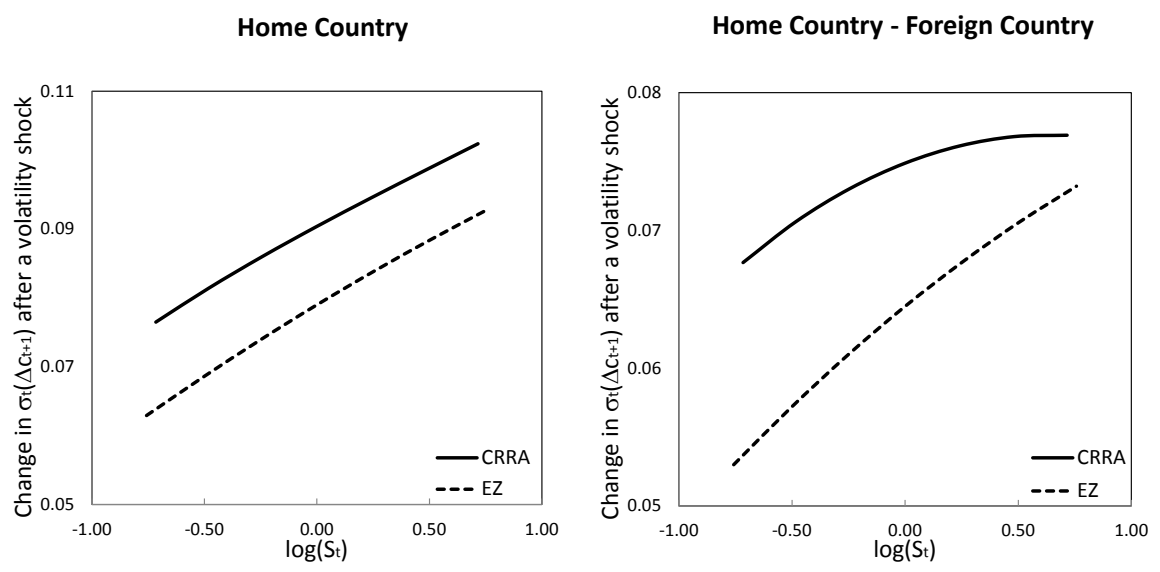

Figure 5 - Response to an Adverse Volatility Shock to Good $X$. The left panel reports the change in the conditional volatilities of consumption growth in the home country after an adverse shock to the volatility of the good $X$. The right panel reports the change in the cross-country difference of conditional volatility of consumption growth for the same shock. In each panel, the dashed (solid) line refers to the case of EZ (CRRA) preferences. Across all experiments, we keep all other exogenous state variables fixed at their unconditional mean.

We conclude this section pointing out that the responses of consumption, net exports, and stochastic discount factors in the model with EZ preferences are the mirror image of those obtained for a positive long-run endowment shock, since a positive volatility shock is a negative news shock.

\subsection{Volatility Comovents and Pass-through}

Unconditional comovements. We use simulations to quantify the ability of the model to reproduce our empirical findings for the dynamics of volatility. We find it useful to consider first a setting with standard CRRA preferences, as in this case shocks do not produce any sizeable endogenous reallocation of volatility from one country to the other. Equivalently, the pseudo-Pareto weights are almost constant 
Table 5: Comovents and Pass-Through

\begin{tabular}{|c|c|c|c|c|}
\hline \multicolumn{5}{|c|}{ Panel A: Unconditional comovements } \\
\hline \multirow{3}{*}{$\begin{array}{l}\operatorname{corr}\left(\sigma_{t}\left(\Delta c_{t+1}\right), \sigma_{t}\left(\Delta y_{t+1}\right)\right. \\
\operatorname{corr}\left(\sigma_{t}\left(\Delta c_{t+1}\right), \sigma_{t}\left(\Delta c_{t+1}^{*}\right)\right)\end{array}$} & Aver. & $\begin{array}{l}\text { Quintiles } \\
{\left[1^{\text {st }} ; 4^{\text {th }}\right]}\end{array}$ & $\begin{array}{c}\text { Bench- } \\
\text { mark }\end{array}$ & $\begin{array}{l}\text { No TVV } \\
\left(\sigma_{\sigma}=0\right)\end{array}$ \\
\hline & 0.65 & {$[0.26 ; 0.80]$} & 0.88 & 0.98 \\
\hline & 0.45 & {$[0.35 ; 0.66]$} & 0.35 & -0.93 \\
\hline \multicolumn{5}{|c|}{ Panel B: Pass-through and size } \\
\hline & & SWC & US vol shock & Foreign vol shock \\
\hline US/G7 Countries: & & {$\left[\begin{array}{lll}0.44 & 0.51\end{array}\right]$} & {$\left[\begin{array}{ll}0.43 & 0.54\end{array}\right]$} & \\
\hline Model (EZ) & \multicolumn{2}{|r|}{0.50} & 0.53 & {$\left[\begin{array}{ll}0.51 & 0.63\end{array}\right]$} \\
\hline Model (CRRA) & \multicolumn{2}{|r|}{0.50} & 0.30 & 0.30 \\
\hline \multicolumn{5}{|c|}{ US/Bottom-10 G17 Countries } \\
\hline \multirow{2}{*}{\multicolumn{2}{|c|}{$\begin{array}{l}\text { Data } \\
\text { Model (EZ) }\end{array}$}} & {$\left[\begin{array}{lll}0.72 & 0.77\end{array}\right]$} & {$\left[\begin{array}{lll}0.45 & 0.57\end{array}\right]$} & {$\left[\begin{array}{ll}0.66 & 0.78\end{array}\right]$} \\
\hline & & 0.72 & 0.39 & 0.70 \\
\hline \multicolumn{2}{|l|}{$\begin{array}{l}\text { Model (EZ) } \\
\text { Model (CRRA) }\end{array}$} & 0.72 & 0.38 & 0.37 \\
\hline
\end{tabular}

Notes - In Panel A, we report correlations between the conditional volatility $\left(\sigma_{t}\right)$ of consumption and output growth within and across countries. Conditional volatilities are obtained by estimating equation (2.1) country-by-country. The data refer to G-17 countries and are described in section 2.1. Panel B reports estimated pass through coefficients (see equation (2.4)) with respect to both domestic (US) and foreign volatility shocks for both the G7 and bottom-10 G17 countries. SWC denotes the share of world consumption, $S /(1+S)$, keeping the U.S. as home country. For each country, we compute the moments of interest over the post-Bretton Wood period, 1971:Q1-2013:Q4. For each moment, we report first and fourth cross-country quintiles. The entries from the model are obtained from 100 repetitions of small samples. Our benchmark quarterly calibration is reported in table 4 .

(Colacito and Croce (2013)), similarly to the autarky scenario in Cole and Obstfeld (1991). In this situation, the correlation between consumption and output volatility within each country is almost perfect, as the volatility of consumption moves one-toone with the volatility of the output growth rate.

The international correlation of the consumption volatilities is $50 \%$, a number slightly higher than the one observed in the data. Recall that the exogenous international correlation of the output volatility shocks is set to $30 \%$. Since the pseudo-Pareto weights are almost fixed under CRRA, the log-consumption bundles in each country 
are a constant weighted average of the two goods, and hence their volatilities are more correlated than those of the two underlying endowment processes.

In contrast to the CRRA case, our model with recursive preferences is able to produce a less than perfect contemporaneous correlation between output and consumption volatility. This result is driven by the fact that level shocks are an important endogenous driver of consumption volatility independently of our exogenous output volatility shocks. As shown in the table, without volatility shocks, the cross-country correlation of the consumption profiles would be almost perfectly negative. This channel counterbalances the tendency of having consumption profiles more correlated than output. At the equilibrium, our model produces a final correlation of $35 \%$, a figure which is well within the confidence region of our cross-section of countries.

Pass-through. Overall, unconditional comovents do not allow us to discriminate between the CRRA and the EZ setting, as both models produce results that lie within the empirical ranges. This conclusion changes when we focus on conditional responses and, in particular, on our pass-through index. When we compare countries of similar size, i.e., US versus the remaining G7 countries, only the model with EZ preferences generates a pass-through of $50 \%$, as in the data. This result is particularly relevant because it is obtained with a simultaneous response of the current account that replicates that observed in the data, as shown in figure 2. Under CRRA preferences, instead, the pass-through is very limited, as volatility news are not an independent determinant of risk-sharing motives.

Furthermore, when we alter the relative consumption share in the model and set the home country consumption to be about three times larger than that of the foreign country, as in the comparison between the US and the bottom-10 G17 countries, our 
model can replicate the asymmetry documented in the data. Specifically, our model predicts that when the volatility shock hits a big country, the pass-through is limited. Vice versa, small countries can better share shocks to their endowment volatility as documented by their higher pass-through. This result follows directly from the convexity of the short-run volatility frontier depicted in the top-left panel of Figure 4 for the case of EZ preferences.

In the CRRA case, instead, the relative country size does not play any major role in determining the extent of volatility pass-through, a result which is at odds with the data. In the next subsection, we show that a model with CRRA preferences fails also in explaining the volatility disconnect in our international data set.

\subsection{Risk-Sharing and Volatility Disconnect Anomaly}

In Table 6, we compare our empirical findings on the disconnect between exchange rates and consumption differentials to our simulation results. In the top panel, we show that our benchmark model is able to replicate the slightly negative correlation between consumption growth differentials and exchange rate movements observed in the data over both at quarterly and an annual horizon. As in the model with constant volatility of Colacito and Croce (2013), news shocks are sufficient to break the perfect correlation of the consumption differentials and the exchange rate. Consistent with the observation in Backus and Smith (1993), under CRRA preferences this correlation is counterfactually high.

Most importantly, with CRRA preferences also the correlation between the conditional variance of consumption differentials and exchange rate's movements is 1 (last column in the bottom portion of Table 6). This outcome is at odds with the 
Table 6: Volatility Disconnect Anomaly and Risk-Sharing

\begin{tabular}{|c|c|c|c|c|c|}
\hline & \multicolumn{2}{|c|}{ G-17 Data } & \multicolumn{3}{|c|}{ Model } \\
\hline & Aver. & $\begin{array}{l}\text { Quintiles } \\
{\left[1^{s t} ; 4^{t h}\right]}\end{array}$ & $\begin{array}{l}\text { Bench- } \\
\text { mark }\end{array}$ & $\begin{array}{l}\text { No TVV } \\
\left(\sigma_{\sigma}=0\right)\end{array}$ & $\begin{array}{l}\text { CRRA } \\
(\gamma=7)\end{array}$ \\
\hline $\begin{array}{c}\text { Levels Disconnect } \\
\operatorname{corr}\left(\Delta c d_{t+1}, \Delta e_{t+1}\right)\end{array}$ & -0.13 & {$[-0.19 ;-0.04]$} & -0.25 & -0.27 & 1.00 \\
\hline $\operatorname{corr}\left(\Delta \widehat{c d}_{t+4}, \Delta \widehat{e}_{t+4}\right)$ & -0.14 & {$[-0.29 ;-0.05]$} & -0.21 & -0.24 & 1.00 \\
\hline $\begin{array}{l}\text { Volatility Disconnect } \\
\operatorname{corr}\left(\sigma_{t}\left(\Delta c d_{t+1}\right), \sigma_{t}\left(\Delta e_{t+1}\right)\right)\end{array}$ & 0.20 & {$\left[\begin{array}{ll}-0.01 & 0.42\end{array}\right]$} & 0.56 & -0.75 & 1.00 \\
\hline $\operatorname{corr}\left(\sigma_{t}\left(\Delta \widehat{c d}_{t+4}\right), \sigma_{t}\left(\Delta \widehat{e}_{t+4}\right)\right)$ & 0.26 & {$\left[\begin{array}{ll}-0.02 & 0.52\end{array}\right]$} & 0.47 & -0.75 & 1.00 \\
\hline
\end{tabular}

Notes - This table reports key moments for real consumption growth differentials $(\Delta c d=$ $\left.\Delta c-\Delta c^{*}\right)$ and exchange rate growth $(\Delta e)$. Foreign variables are marked by ${ }^{(*}$; cumulative growth rates are denoted by ' $\wedge$ '. Conditional log-volatilities are denoted by $\sigma_{t}$. The empirical moments are obtained by estimating equation (2.1) country-by-country, as detailed in section 2.2. The data refer to G-17 countries and are described in section 2.1. For each country, we compute the moments of interest over the post-Bretton Wood period, 1971:Q1-2013:Q4, as detailed in section 2.1. For each moment, we report (i) its GDPweighted average across countries; and (ii) its first and fourth cross-country quintiles. The entries from the model are obtained from 100 repetitions of small samples. Our benchmark quarterly calibration is reported in table 4 .

findings of our empirical investigation and can be explained by looking at the right panels of Figure 6, regardless of whether a volatility shock, a short-run shock, or a long-run shock hits the economy, the two set of volatilities are always characterized by a perfect degree of co-movement.

In our benchmark model, instead, the behavior of the volatilities depends on the nature of the specific shock hitting the economy (Figure 6, left panels). Specifically, a volatility shock in the home country is still characterized by a positive co-movement between exchange rate and differential of consumption growth rates. This is because the two countries share the risk associated to an increase in macroeconomic uncertainty, as explained in the previous section. 
EZ Preferences
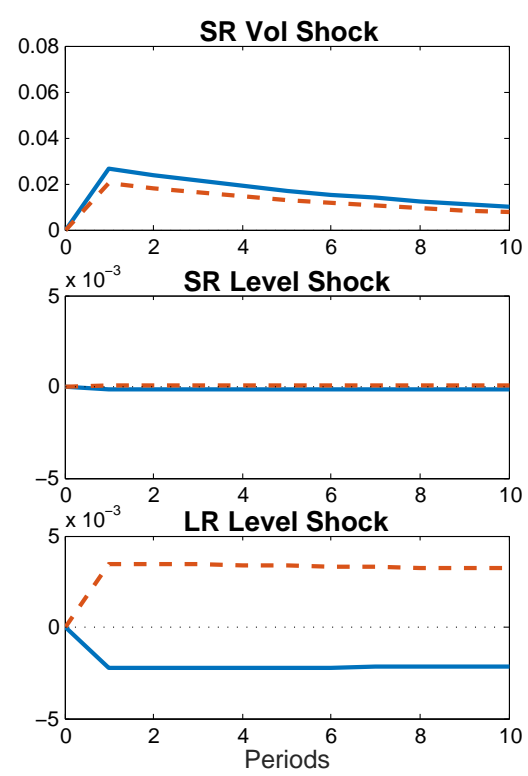

CRRA Preferences

SR Vol Shock
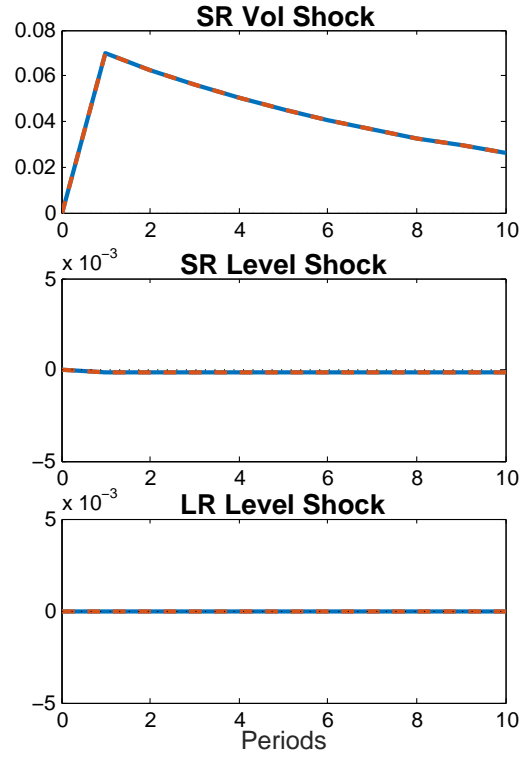

$\sigma(\Delta e)---\sigma(\Delta c-\Delta c f)$

Figure 6 - Impulse Response Functions and Volatility Disconnect. This figure shows the percentage response of the volatility of consumption growth differentials (dashed line) and exchange rate's growth rate volatility (thick line) to a volatility shock in the home country (top panels), a short-run shock in the home country (middle panels), and a long-run shock in the home country (bottom panels), respectively. The left (right) panels report the response functions for our benchmark model with EZ (CRRA) preferences.

We note that short-run shocks are irrelevant in this context, as they result in a negligible response of the two volatilities, since investors' marginal utilities are not particularly sensitive to this type of shocks (mid-left panel of Figure 6). In contrast, a long-run shock to the home country generates a significant negative co-movement between the two volatilities and lowers their unconditional correlation (bottom-left panel of Figure 6). Over an annual horizon, this channel enables our model to produce a correlation well within our empirical range (Table 6, bottom two lines). 
In order to explain the origin of such negative comovement, it is useful to decompose the variance of the consumption differential growth rate in its subcomponents:

$$
\begin{aligned}
\operatorname{Var}_{t}\left(\Delta c_{t+1}-\Delta c_{t+1}^{*}\right)= & \operatorname{Var}_{t}\left(\Delta c_{t+1}\right)+\operatorname{Var}_{t}\left(\Delta c_{t+1}^{*}\right) \\
& -2 \cdot \sqrt{\operatorname{Var}_{t}\left(\Delta c_{t+1}\right) \cdot \operatorname{Var}_{t}\left(\Delta c_{t+1}^{*}\right)} \cdot \operatorname{corr}\left(\Delta c_{t+1}, \Delta c_{t+1}\right)
\end{aligned}
$$

Given the small adjustment of the conditional correlation of consumption growth rates produced in our setting (see Figure 7), the dynamics of the variance of consumption differentials is determined by the sum of the variances of the consumption growth rates across countries. Because of the convexity of the short-run volatility frontier depicted in the top-left panel of Figure 4 (dashed line), this sum is increasing in wealth inequality, i.e., it is U-shaped with respect to the log-ratio of the Pareto weights (Figure 8). As a result, starting from an equal distribution of wealth, $\sigma_{t}\left(\Delta c_{t+1}-\right.$ $\Delta c_{t+1}^{*}$ ) increases upon the arrival of a positive long-run shock (Figure 6, bottom-left panel).

Given our complete markets' assumption, the variance of the exchange rate growth can be decomposed as follows,

$$
\begin{aligned}
\operatorname{Var}_{t}\left(\Delta e_{t+1}\right)= & \operatorname{Var}_{t}\left(\Delta m_{t+1}-\Delta m_{t+1}^{*}\right) \\
= & \operatorname{Var}_{t}\left(\Delta m_{t+1}\right)+\operatorname{Var}_{t}\left(\Delta m_{t+1}^{*}\right) \\
& -2 \sqrt{\operatorname{Var}_{t}\left(\Delta m_{t+1}\right) \cdot \operatorname{Var}_{t}\left(\Delta m_{t+1}^{*}\right)} \cdot \operatorname{corr}\left(\Delta m_{t+1}, \Delta m_{t+1}\right) .
\end{aligned}
$$

In a model with long-run growth news most of the volatility of the stochastic discount rates is driven by the continuation utilities. As shown in the top-right panel of Fig- 


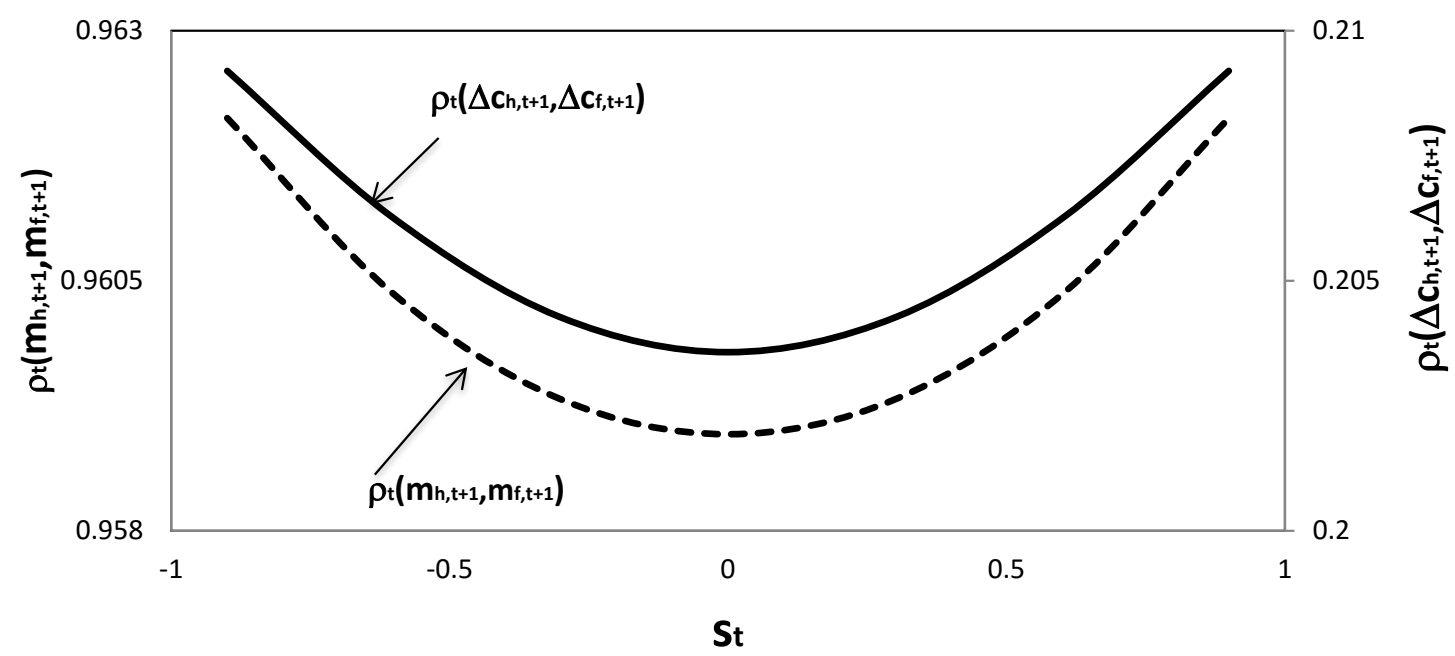

Figure 7 - Conditional Correlations. The dashed line reports the conditional correlations of the stochastic discount factors as a function of the logarithm of the ratio of the pseudo Pareto weights. The thick line shows the conditional correlations of the growth rates of consumption as a function of the logarithm of the ratio of the pseudo-Pareto weights. Across all experiments, we keep both the exogenous long-run components and the exogenous volatility processes fixed at their unconditional mean.

ure 4, the utility variance frontier is linear, meaning that the drop in the conditional volatility of the utility of one country is almost entirely offset by the increase in volatility of the other country. As a result, $\operatorname{Var}_{t}\left(\Delta m_{t+1}\right)+\operatorname{Var}_{t}\left(\Delta m_{t+1}^{*}\right)$ is time-invariant. Given the higher correlation of the stochastic discount factors that is associated to the enhanced risk-sharing opportunity (see Figure 7), the exchange rate volatility has an inverse U-shape with respect to the log-ratio of the Pareto weights (Figure 8). Equivalently, starting from an equal distribution of wealth, the impulse response of the exchange rate volatility is negative.

We conclude our analysis by noting that without volatility shocks, e.g., the case considered in (Colacito and Croce, 2013)), the volatility disconnect generated by our 


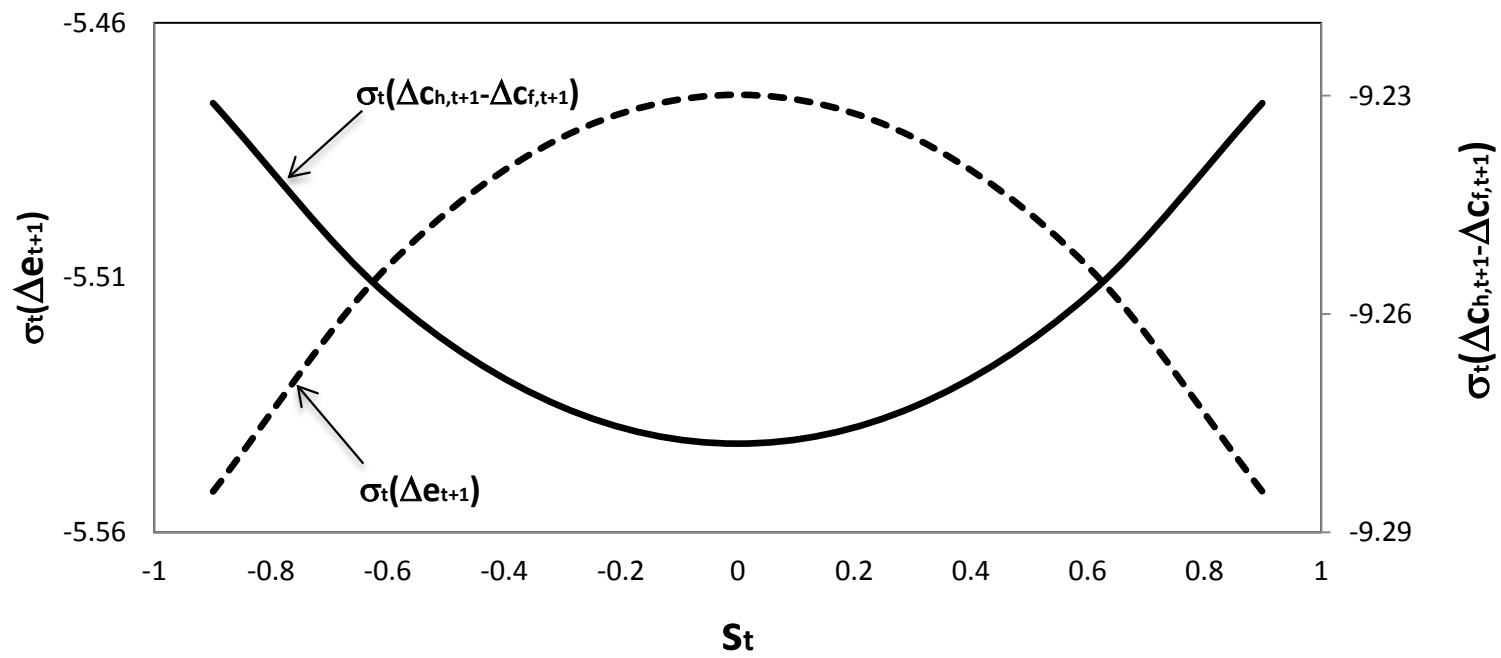

Figure 8 - Conditional Volatilities Disconnect. The Figure plots the logarithm of the conditional volatility of the growth rate of the exchange rate $\left(\sigma_{t}\left(\Delta e_{t+1}\right)\right)$ on the left vertical axis, and the logarithm of the conditional volatility of difference between the growth rate of consumption in the home and foreign countries $\left(\sigma_{t}\left(\Delta c_{h, t+1}-\Delta c_{f, t+1}\right)\right)$ on the right vertical axis. Both volatilities are plotted against the logarithm of the ratio of pseudo Pareto weights $\left(s_{t}\right)$. Across all experiments, we keep both the exogenous long-run components and the exogenous volatility processes fixed at their unconditional mean.

model would be counterfactually large. This is because of the predominance of the endogenous response of volatilities to long-run shocks, which results in a negative correlation. We regard the ability of our benchmark model to match the correlation between the volatilities of consumption growth differentials and exchange rate's fluctuations as an important finding, which further highlights the relevance of volatility shocks in enhancing our understanding of the dynamics of international asset pricing and quantities.

\section{Conclusion}

In this paper, we construct a measure of bilateral volatility pass-through and we use it to document the sizeable extent of international propagation of output volatility 
shocks. Furthermore, we provide novel empirical evidence about the disconnect between the volatility of consumption differentials and the volatility of exchange rates. We show that these finding constitute a puzzle from the standpoint of a frictionless model with CRRA preferences. We then develop a frictionless general equilibrium model featuring long-run growth news shocks, volatility shocks, and two countries populated by agents with recursive preferences that can replicate these empirical findings.

Future developments should focus on extending this setting to international real business cycle models in an effort of studying the role of international investment flows and international frictions for the origination and international propagation of volatility shocks. The investigation of the roles of trading frictions, portfolio composition, and market incompleteness are other promising directions for future research. 


\section{References}

Backus, D. K., F. Gavazzoni, C. Telmer, and S. E. Zin, (2010), Monetary policy and the uncovered interest parity puzzle Working Paper, NBER.

Backus, D. K., P. J. Kehoe, and F. E. Kydland, (1994), Dynamics of the trade balance and the terms of trade: The j-curve?, The American Economic Review 84, 84-103.

Backus, D. K. and G. Smith, (1993), Consumption and real exchange rates in dynamic economies with non-traded goods, Journal of International Economics 35, 297316.

Balta, N. and J. Delgado, (2007), Home Bias and market Integration in the EU Working Paper, BRUEGEL.

Bansal, R., D. Kiku, I. Shaliastovich, and A. Yaron, (2014), Volatility, the macroeconomy, and asset prices, Journal of Finance 69, 2471-511.

Bansal, R. and I. Shaliastovich, (2013), A long-run risks explanation of predictability puzzles in bond and currency markets, Review of Financial Studies 26, 1-33.

Basu, S. and B. Bundick, (2012), Uncertainty shocks in a model of effective demand, NBER Working Paper No. 18420.

Bloom, N., (2009), The impact of uncertainty shocks, Econometrica 77(3), 623-689.

Chernov, M., J. Graveline, and I. Zviadadze, (2015), Crash risk in currency returns, Working Paper.

Cogley, T. and T. J. Sargent, (2005), Drifts and volatilities: monetary policies and outcomes in the post WWII US, Review of Economic Dynamics 8. 
Colacito, R., (2008), Six anomalies looking for a model. a consumption based explanation of international finance puzzles., Working Paper, Department of Finance, University of North Carolina, Chapel Hill NC .

Colacito, R. and M. Croce, (2013), International asset pricing with recursive preferences, Journal of Finance 68, 2651-86.

Colacito, R. and M. M. Croce, (2011), Risks for the long run and the real exchange rate, Journal of Political Economy .

Colacito, R. and M. M. Croce, (2012), Recursive allocations and wealth distribution with multiple goods, Working paper.

Cole, H. and M. Obstfeld, (1991), Commodity trade and international risk sharing. how much do financial markets matter?, Journal of Monetary Economics 28, $3-24$.

Cortet, P. D., L. Sarno, and I. Tsiakas, (2009), An Economic Evaluation of Empirical Exchange Rate Models, Review of Financial Studies 22(9).

Epstein, L. G. and S. Zin, (1991), Substitution, risk aversion and the temporal behavior of consumption and asset returns: An empirical analysis, Journal of Political Economy 99, 263-286.

Erceg, C., L. Guerrieri, and C. Gust, (2008), Trade Adjustment and the Composition of Trade, Journal of Economic Dynamics and Control 32(8).

Farhi, E., S. Fraiberger, X. Gabaix, R. Ranciere, and A. Verdelhan, (2015), Crash risk in currency markets, Working Paper, Harvard and NYU .

Farhi, E. and X. Gabaix, (2008), Rare disasters and exchange rates, Working paper. 
Fernandez-Villaverde, J., P. Guerron-Quintana, J. F. Rubio-Ramirez, and M. Uribe, (2011), Risk matters: The real effects of volatility shocks, American Economic Review 101.

Fogli, A. and F. Perri, (2015), Macroeconomic volatility and external imbalances, Journal of Monetary Economics 69.

Gabaix, X. and M. Maggiori, (2015), International liquidity and exchange rate dynamics, Quarterly Journal of Economics, forthcoming .

Gavazzoni, F., B. Sambalaibat, and C. Telmer, (2013), Currency risk and pricing kernel, Working Paper .

Gilchrist, S., J. Sim, and E. Zakrajsek, (2014), Uncertainty, financial frictions and investment dynamics, NBER Working Paper No. 20038.

Gourio, F., M. Siemer, and A. Verdelhan, (2014), Uncertainty and international capital flows Working Paper.

Hassan, T., (2013), Country size, currency unions, and international asset returns, The Journal of Finance 68(6), 2269-2308.

Heyerdahl-Larsen, C., (2015), Asset Prices and Real Exchange Rates with Deep Habits., Review of Financial Studies .

Jones, L., R. Manuelli, H. Siu, and E. Stacchetti, (2005), Fluctuations in convex models of endogenous growth I: Growth effects, Review of Economic Dynamics $8,780-804$.

Jurado, K., S. Ng, and S. Ludvigson, (2014), Measuring uncertainty, American Economic Review . 
Justiniano, A. and G. E. Primiceri, (2008), The time-varying volatility of macroeconomic fluctuations, American Economic Review 98.

Kim, S., N. Shephard, and S. Chib, (1998), Stochastic volatility: Likelihood inference and comparison with ARCH models, Review of Economic Studies 65, 361-93.

Lettau, M., S. Ludvigson, and J. Wachter, (2006), The declining equity premium: What role does macroeconomic risk play?, Forthcoming in Review of Financial Studies.

Lustig, H., N. Roussanov, and A. Verdelhan, (2011), Common risk factors in currency markets, Review of Financial Studies 24(11), 3731-3777.

Maggiori, M., (2011), Financial intermediation, international risk sharing, and reserve currencies Working paper.

McConnell, M. and G. P. Quiros, (2000), Output fluctuations in the united states: What has changed since the early 1980s?, American Economic Review 90, 146476.

Mueller, P., A. Stathopoulos, and A. Vedolin, (2015), International correlation risk, Working Paper.

Nakamura, E., D. Sergeyev, and J. Steinsson, (2012), Growth-Rate and Uncertainty Shocks in Consumption: Cross-Country Evidence Working Paper.

Novy, D. and A. M. Taylor, (2014), Trade and uncertainty Working Paper.

Obstfeld, M., (1998), The global capital market: Benefactor or menace?, Journal of Economic Perspectives 12, 9-30. 
Primiceri, G. E., (2005), Time Varying Structural Vector Autoregressions and Monetary Policy, Review of Economic Dynamics 72(3).

Quinn, D. P., (1997), The correlates of change in international financial regulation, American Political Science Review 91(3), 531-551.

Quinn, D. P. and H.-J. Voth, (2008), A century of global equity markets correlations 98.

Ramey, G. and V. Ramey, (1995), Cross-country evidence on the link between volatility and growth, American Economic Review 85, 1138-1151.

Ready, R., N. Roussanov, and C. Ward, (2012), Commodity Trade and the Carry Trade: A Tale of Two Countries Working Paper, the Wharton School.

Stathopoulos, A., (2012), Asset prices and risk sharing in open economies, Working Paper, University of Washington .

Stock, J. and M. Watson, (2002), Has the business cycle changed and why, in Gertler, M. and K. Rogoff, eds., NBER Macroeconomics Annual: 2002, MIT Press, Cambridge, MA.

Taylor, A. M., (2002), A century of current account dynamics, Journal of International Money and Finance 21, 725-748.

Verdelhan, A., (2010), A habit-based explanation of the exchange rate risk premium, The Journal of Finance 65(1), 123-145.

Zviadadze, I., (2015), Term structure of consumption risk premia in the cross section of currency returns, Working Paper . 


\section{Appendix A. Volatility Estimation}

We use auxiliary mixture sampler to estimate the model specified in (2.1) and extract latent volatility components, following Kim, Shephard, and Chib (1998). Specifically, we rewrite the observation equation,

$$
\log \left(\left(z_{t}-\mu-\rho z_{t-1}\right)^{2}\right)=\sigma_{t}+\log \left(\eta_{t}^{2}\right)
$$

The distribution of $\log \left(\eta_{t}^{2}\right)$ can be well approximated by a mixture of Gaussian distributions:

$$
p\left(\log \left(\eta_{t}^{2}\right)\right)=\Sigma_{i=1}^{n} \pi_{i} \varphi\left(\eta_{t} ; \mu_{, \eta i}, \sigma_{\eta, i}^{2}\right)
$$

where $\varphi$ is the probability density function of a Gaussian distribution with mean $\mu_{\eta, i}$ and standard deviation $\sigma_{\eta, i}$. In the Markov Chain Monte Carlo procedure, $s_{t} \in[1, T]$ is drawn to indicate one Gaussian distribution to sample $\log \left(\eta_{t}^{2}\right)$. Conditioning on $s_{t}$, the model is in Gaussian linear state-space form, and standard forward filtering backward sampling scheme can be applied. The algorithm thus takes the form:

1. Initialize $\mu, \rho, \mu_{\sigma}, \nu, \sigma_{\omega}, s_{t}$

2. Sample $\sigma_{t}$ from $p\left(\sigma_{t} \mid z, \mu, \rho, \mu_{\sigma}, \nu, \sigma_{\omega}, s_{t}, z\right)$

3. Sample $s_{t}$ from $p\left(s_{t}=i\right) \propto \pi_{i} \varphi\left(\log \left(\left(z_{t}-\mu-\rho z_{t-1}\right)^{2}\right) ; \sigma_{t}+\mu_{\eta, i}, \sigma_{\eta, i}^{2}\right)$

4. Sample $\mu, \rho, \mu_{\sigma}, \nu, \sigma_{\omega}$ from $p\left(\mu, \rho, \mu_{\sigma}, \nu, \sigma_{\omega} \mid \sigma_{t}, z\right)$

5. Repeat 2-4 until convergence

In our empirical implementation the priors are very loose: $\mu \sim N(0.005,2), \rho \sim$ $N(0.3,100), \mu_{\sigma} \sim N(-10,20), \nu \sim N(0.9,0.5)$, and $\sigma_{\omega} \sim I G(2,0.5)$. We sampled 20,000 times and discard the first 5,000. The posterior mean of $\sigma_{t}$ is the volatility used in the empirical analysis.

\section{Appendix A.1. Robustness of Empirical Results}

We verify that our key empirical evidence on the volatility risk sharing is quite robust to modifications of the benchmark analysis. Specifically, we consider all the G17 countries, 
Table A1: Robustness of Pass-Through Results

\begin{tabular}{|c|c|c|c|c|c|}
\hline \multicolumn{6}{|c|}{ Panel A: Contemporaneous adjustments to relative volatility shocks } \\
\hline$\sigma(\Delta y)$ & $\Delta y$ & $\sigma(\Delta c)$ & $\Delta c$ & $\Delta(N X / Y)$ & $\begin{array}{c}\text { Pass- } \\
\text { through }\end{array}$ \\
\hline \multicolumn{6}{|c|}{ Global Benchmark, G17 Countries: } \\
\hline 0.16 & -0.44 & 0.06 & -0.06 & \multirow{2}{*}{$\begin{array}{c}-0.37 \\
{[-0.56 ;-0.18]}\end{array}$} & 0.61 \\
\hline$[0.15 ; 0.16]$ & {$[-0.67 ;-0.21]$} & {$[0.06 ; 0.07]$} & {$[-0.20 ; 0.09]$} & & {$[0.57 ; 0.64]$} \\
\hline \multicolumn{6}{|c|}{ US/Pooled G6: } \\
\hline 0.19 & -0.52 & 0.09 & -0.26 & \multirow{2}{*}{$\begin{array}{c}-0.26 \\
{[-0.49 ;-0.03]}\end{array}$} & 0.53 \\
\hline$[0.19 ; 0.20]$ & {$[-0.83 ;-0.23]$} & {$[0.08 ; 0.10]$} & {$[-0.50 ;-0.02]$} & & {$[0.49 ; 0.56]$} \\
\hline \multicolumn{6}{|c|}{ VAR(2) Model: } \\
\hline 0.21 & -0.41 & 0.09 & -0.11 & \multirow{2}{*}{$\begin{array}{c}-0.29 \\
{[-0.53 ;-0.06]}\end{array}$} & 0.59 \\
\hline$[0.20 ; 0.21]$ & {$[-0.71 ;-0.11]$} & {$[0.08 ; 0.09]$} & {$[-0.34 ; 0.13]$} & & {$[0.55 ; 0.62]$} \\
\hline \multicolumn{6}{|c|}{ Panel B: Pass-through and size } \\
\hline \multirow{4}{*}{\multicolumn{3}{|c|}{ Global Benchmark/G17 Countries: }} & \multicolumn{3}{|c|}{ Origin of Vol. Shock: } \\
\hline & & & U.S. & & eign Country \\
\hline & & & 0.52 & & 0.62 \\
\hline & & & {$[0.45 ; 0.59]$} & & {$[0.58 ; 0.66]$} \\
\hline \multicolumn{3}{|c|}{ US/Pooled G6: } & $\begin{array}{c}0.47 \\
{[0.43 ; 0.52]}\end{array}$ & & $\begin{array}{c}0.64 \\
{[0.58 ; 0.70]}\end{array}$ \\
\hline \multicolumn{3}{|l|}{$\operatorname{VAR}(2):$} & $\begin{array}{c}0.55 \\
{[0.50 ; 0.60]}\end{array}$ & & $\begin{array}{c}0.63 \\
{[0.58 ; 0.68]}\end{array}$ \\
\hline
\end{tabular}

Notes - Panel A shows the estimates of the contemporaneous responses $\left(\widetilde{\Sigma}_{1 j}\right)$ of the VAR specified in equations $(2.2)-(2.3)$ with respect to a shock to relative output volatility. Response of output growth, consumption growth, and net exports to output are annualized, in per cent. Volatility pass-through is defined as in equation (2.4). "Global Benchmark" is defined as the weighted average of the corresponding series across all countries. In "Pooled G6" specification, we estimte macroeconomic volatility assuming that the volatility parameters are the same across countries. "VAR(2)" stands for 2-lag VAR with US/G7 countries. Panel B reports pass-through measures based on the estimates of the VAR in equation (2.5)-2.6) with respect to volatility shocks affecting either the benchmark or the remaining countries. $95 \%$ confidence intervals are reported in the brackets. Our quarterly data range from 1971:q1 to 2013:q4.

and using global benchmark, defined as the average of the corresponding series across all countries, in place of the U.S.

We also consider estimating macroeconomic volatility assuming that the volatility parameters are the same across countries pooling the macroeconomic series across countries, 
and pooling the data. As shown in Table A1, our main empirical results are quite robust to all the specifications. Relative consumption and output generally decline and consumption volatility increases due to a volatility shocks, and the effects on consumption are smaller than on output. The relative magnitudes of the effects are quite stable across the specifications; for example, the estimate of the volatility pass-through ranges from 0.43 for G17 to 0.48 for the $\mathrm{G} 7$ countries.

Table A1 shows that the robustness of our evidence for the size effects. 


\section{Appendix B. Standard Moments from the Model}

In Table B2, we focus on unconditional moments typically targeted in the international finance literature. Our benchmark calibration conforms well with our data, both with and without volatility shocks. The adoption of CRRA preferences, generates well known puzzles: (i) the market price of risk is excessively low; (ii) the risk-free rate is too high; and (iii) international trade is modest. In our model the net exports are not as volatile as in our G17 dataset, but they are twice as volatile compared to the CRRA case.

Table B2: Standard Unconditional Moments

\begin{tabular}{|c|c|c|c|c|c|}
\hline & \multicolumn{2}{|c|}{ G-17 Data } & \multicolumn{3}{|c|}{ Model } \\
\hline & Aver. & $\begin{array}{c}\text { Quintiles } \\
{\left[1^{s t} ; 4^{\text {th }}\right]}\end{array}$ & $\begin{array}{c}\text { Bench- } \\
\text { mark }\end{array}$ & $\begin{array}{l}\text { No TVV } \\
\left(\sigma_{\sigma}=0\right)\end{array}$ & $\begin{array}{l}\text { CRRA } \\
(\gamma=7)\end{array}$ \\
\hline $\operatorname{corr}\left(\Delta c, \Delta c^{*}\right)$ & 0.25 & {$[0.13 ; 0.33]$} & 0.38 & 0.37 & 0.74 \\
\hline$\sigma(\Delta c)(\%)$ & 1.67 & {$[1.34 ; 2.47]$} & 1.85 & 1.82 & 1.64 \\
\hline$\sigma(\Delta c) / \sigma(\Delta y)$ & 0.88 & {$[0.57 ; 0.82]$} & 0.93 & 0.94 & 0.83 \\
\hline$A C F 1(\Delta c)$ & 0.17 & {$[-0.16 ; 0.31]$} & 0.06 & 0.07 & 0.08 \\
\hline$\sigma(M) / E(M)(\%)$ & - & - & 47.86 & 47.85 & 11.49 \\
\hline$\sigma(\Delta e)(\%)$ & 10.50 & {$[10.2 ; 11.4]$} & 12.80 & 12.65 & 8.31 \\
\hline$E\left(r^{f}\right)(\%)$ & 1.35 & {$[1.44 ; 2.41]$} & 2.17 & 2.19 & 14.91 \\
\hline$\sigma\left(r^{f}\right)(\%)$ & 1.79 & {$[1.61 ; 2.27]$} & 0.33 & 0.33 & 3.47 \\
\hline $\operatorname{corr}\left(r^{f}, r^{f *}\right)$ & 0.51 & {$[0.37 ; 0.56]$} & 0.91 & 0.92 & 0.98 \\
\hline$\sigma(\Delta(N X / Y)) / \sigma(\Delta y)$ & 0.70 & {$[0.67 ; 0.97]$} & 0.32 & 0.32 & 0.16 \\
\hline
\end{tabular}

Notes - This table reports key moments for real consumption $(C)$, output $(Y)$, exchange rate $(E)$, risk-free rates $\left(R^{f}\right)$, net-export-to-output ratio $(N X / Y)$, and stochastic discount factor $(M)$. Small letters refer to log-units; changes are denoted by ' $\Delta^{\prime}$; foreign variables are marked by '*'. We denote expectation, standard deviation, correlation, and first order autocorrelation by $E, \sigma, c o r r$, and $A C F 1$, respectively. The data refer to G-17 countries and are described in section 2.1. For each country, we compute the moments of interest over the post-Bretton Wood period, 1971:Q1-2013:Q4, as detailed in section 2.1. For each moment, we report (i) its GDP-weighted average across countries; and (ii) its first and fourth crosscountry quintiles. The entries from the model are obtained from 100 repetitions of small samples. Our benchmark quarterly calibration is reported in table 4. 